\title{
Structure and evolution of Subtropical Cyclone Anita as evaluated by heat and vorticity budgets
}

Article

Accepted Version

Dutra, L. M. M., da Rocha, R. P., Lee, R. W., Peres, J. R. R. and de Camargo, R. (2017) Structure and evolution of Subtropical Cyclone Anita as evaluated by heat and vorticity budgets. Quarterly Journal of the Royal Meteorological Society, 143 (704). pp. 1539-1553. ISSN 1477-870X doi: https://doi.org/10.1002/qj.3024 Available at https://centaur.reading.ac.uk/69296/

It is advisable to refer to the publisher's version if you intend to cite from the work. See Guidance on citing.

Published version at: http://onlinelibrary.wiley.com/doi/10.1002/qj.3024/abstract

To link to this article DOI: http://dx.doi.org/10.1002/qj.3024

Publisher: Royal Meteorological Society

All outputs in CentAUR are protected by Intellectual Property Rights law, including copyright law. Copyright and IPR is retained by the creators or other copyright holders. Terms and conditions for use of this material are defined in the End User Agreement. 


\section{CentAUR}

Central Archive at the University of Reading

Reading's research outputs online 


\section{Structure and evolution of Subtropical Cyclone Anita as evaluated}

\section{by heat and vorticity budgets}

Lívia Márcia Mosso Dutra, ${ }^{\mathrm{a} *}$ Rosmeri Porfírio da Rocha, ${ }^{\mathrm{a}}$ Robert William Lee, ${ }^{\mathrm{b}}$

Jean Rafael Romão Peres ${ }^{\mathrm{a}}$ and Ricardo de Camargo ${ }^{\mathrm{a}}$

${ }^{a}$ Departamento de Ciências Atmosféricas, Instituto de Astronomia, Geofísica e Ciências Atmosféricas, Universidade de São Paulo, São Paulo, Brazil.

${ }^{\mathrm{b}}$ Department of Meteorology, University of Reading, Reading, United Kingdom.

*Correspondence to: Lívia Dutra, Universidade de São Paulo, Instituto de Astronomia, Geofísica e Ciências Atmosféricas, Rua do Matão, 1226, Cidade Universitária, São Paulo/SP, Brazil. E-mail: livia.dutra@ iag.usp.br

This paper explores the evolution of subtropical cyclone Anita, which occurred near the east coast of Brazil $\left(\sim 19^{\circ} \mathrm{S}-37^{\circ} \mathrm{W}\right)$ in March 2010. Thermodynamic and dynamic processes during Anita's lifecycle are investigated using the heat and vorticity budget equations. The cyclone developed with hybrid characteristics and moved anomalously to the southwest where it coupled with an upper level cut-off low during the mature phase. This coupling was the main dynamical mechanism for further cyclone deepening. Anita then remained quasi-stationary about $30^{\circ} \mathrm{S}-47^{\circ} \mathrm{W}$ for two days due to an upper level dipole pattern which prevented earlier displacement of the upper level low counterpart. When the dipole pattern dissipated, the cyclone moved southeast and underwent extratropical transition whilst merging with a mid-latitude frontal cyclone. Diabatic heating and horizontal temperature advection are found to be essential for the subtropical development. During extratropical transition, it is instead diabatic cooling together with adiabatic cooling and warm air advection that act as the main mechanisms to influence the local temperature tendencies at low levels. Low level cyclonic tendencies were mostly due to convergent flow, and the residual vorticity partially destroyed the vorticity tendencies produced by the divergence term. Moreover, in regions and levels where convection could explain some of the vorticity tendencies, it is found that apparent sinks of cyclonic vorticity were related to negative vorticity due to divergence (i.e., convergent flow), whilst apparent sources were related to positive vorticity due to divergence (i.e., divergent flow).

Key Words: Subtropical Cyclones; Heat Budget; Vorticity Budget; Anita; South Atlantic Ocean; Brazil

This article has been accepted for publication and undergone full peer review but has not been through the copyediting, typesetting, pagination and proofreading process, which may lead to differences between this version and the Version of Record. Please cite this article as doi: $10.1002 / \mathrm{qj} .3024$ 


\section{Introduction}

In recent years, there has been an increase in the number of studies on subtropical cyclones (STCs) occurring in different regions of the globe. Although there is still no widely accept definition, STCs are described as synoptic scale phenomena with a warm core at low levels and a cold core in the upper troposphere, i.e., they present characteristics of both extratropical and tropical cyclones simultaneously (Hart 2003; Davis 2010). Like their extratropical and tropical counterparts, STCs can directly affect weather conditions over land and sea, producing a variety of hazards, damage, destruction and sometimes significant loss of life.

Some dynamic and thermodynamic processes associated with STC genesis and evolution have been investigated in recent literature (e.g. Guishard et al. 2007, 2009; Evans and Guishard 2009; Davis 2010; Evans and Braun 2012; Gozzo et al. 2014; González-Alemán et al. 2015; Bentley et al. 2016) but are not yet fully understood. Additionally, the main characteristics and physical mechanisms during STCs development can vary depending on which region of the globe they occur. A brief review of some of these studies is given in the following paragraphs.

For the North Atlantic region, Evans and Guishard (2009) found that STC formation is strongly linked with the equatorward intrusion of an upper level trough in the westerlies over a region of relatively warm sea surface temperature (SST) and weak static stability. More than half of all STCs considered by Evans and Guishard (2009) developed over a relatively high vertical wind shear (in excess of $10 \mathrm{~m} \mathrm{~s}^{-1}$ ).

In the north-central Pacific, the STCs occurring in the cold season are named Kona lows and they have large contribution to the precipitation totals in some regions of Hawaii (Simpson 1952; Morrison and Businger 2001; Otkin and Martin 2004; Caruso and Businger 2006; Moore et al. 2008). The pioneering work of Simpson (1952) described Kona lows as essentially cold core systems which can, in some cases, develop warm core properties and a wind field similar to that of tropical cyclones. Simpson (1952) describes the mechanism for this as follows: pressure falls in the upper troposphere (e.g. a merger of a cutoff low with a deepening polar trough) are likely associated with the initial deepening at the surface, which leads to intense precipitation and large release of latent heat (from condensation) near the low center; this release leads to warming and changes of temperature gradients, making the lower core warmer than its surroundings, increasing wind intensities and further deepening the cyclone. Moore et al. (2008) performed a composite analysis of 43 Kona lows and proposed the downstream development as the main dynamical forcing for the STCs geneses.

In the east coast of Australia, intense STCs develop between $25^{\circ} \mathrm{S}-45^{\circ} \mathrm{S}$ throughout the year, mostly in late autumn and early winter (Holland et al. 1987; Browning and Goodwin 2013). STCs occurring in the Tasman Sea region are known as East Coast Cyclones (ECCs) and are typically characterized by widespread heavy rainfall (Hopkins and Holland 1997). ECCs genesis occur in the presence of warm SST anomalies and their intensification is associated with strong zonal SST gradients near to the coastline according to Hopkins and Holland (1997).

For the South Atlantic basin, Evans and Braun (2012) and Gozzo et al. (2014) constructed climatologies of STCs using different reanalysis project datasets and different objective identification techniques. According to Evans and Braun (2012), South Atlantic STCs can develop in environments with a large range of vertical wind shear and SST values. These authors proposed two main genesis mechanisms: Rossby wave breaking and lee cyclogenesis. From the analysis of Gozzo et al. (2014), STCs formation is mainly associated with the presence of a dipole-blocking pattern in the upper troposphere and occurs over a region of relatively weak turbulent latent and sensible heat fluxes near surface.

The contributions of both baroclinic (upper level trough) and diabatic (latent heat releasing during convection) processes are often important during the development of these hybrid STC structures (Bentley et al. 2016). According to the American Meteorological Society (AMS) glossary, STCs extract available potential energy from the mean flow, similar to extratropical cyclones, and at the same time they also receive part or most of their energy from convective redistribution of heat originating from the sea, similar to tropical cyclones (AMS 2016). From this perspective, Bentley et al. (2016) developed a new objective identification technique based on the potential vorticity 
to construct a climatology of STCs that undergo tropical transition over the North Atlantic.

The relative role of dynamic (baroclinic or barotropic instabilities) and diabatic processes (mainly convection) acting during STCs development may also be accessed using the budgets of vorticity and heat. Studies using these equations are important to understand the mechanisms controlling the development of meteorological systems. When computed in synoptio scale, the vorticity and thermodynamic equations usually provide regions/periods of intense values, which are called as siduals. These residuals indicate regions/periods of imbalances that may reflect the presence of intense convective activity. Thermodynamic analyses have been extensively performed in studies investigating extratropical cyclones (e.g. Lipu and Elsberry 1987; Hirschberg and Fritsch 1991; Lupo et al. 1992; Rolfson and Smith 1996) and tropical cyclones (e.g. MicBride 1981; Wang 2012; Fritz and Wang 2014). The vorticity equation has also been extensively used in previous investigations of extratropical cyclones (e.g. Lupo et al. 1992; rotjahn 1996; Azad and Sorteberg 2014a,b), tropical cyclones

(e.g. Karyampudi and Pierce 2002; Raymond and López Carrillo 2011) and even hurricanes that underwent extratropical transition (e.g. DiMego and Bosart 1982; Sinclair 1993). However, similar studies are lacking for STCs. The work of Morrison and Businger (2001), for instance, applied the vorticity tendency equation to explore some of the dynamics features of a Kona low occurred over the north-central Pacific.

In March 2010 a STC developed in subtropical latitudes of the South Atlantic Ocean and, as it moved, it affected weather conditions in coastal areas of South America. Due to its unusual southwest trajectory, this STC soon gained attention from several meteorological institutions around the world. The United States Naval Research Laboratory (NRL) began to monitor it under the name Invest 90Q. Additionally, some Brazilian meteorological centers named it as Anita (Atmosfera Meteorologia 2010). Hereafter, we also use Anita to refer to this cyclone. Some numerical weather prediction models indicated that the STC would move to the southwest, with chances of acquiring some tropical cyclone characteristics, as occurred in 2004 with the Catarina cyclone, the first-ever reported hurricane in the South Atlantic basin (Pezza and Simmonds 2005). The potential of Anita to undergo a tropical transition was explored by Dias Pinto et al. (2013) through synoptic and energy cycle analyses. They verified that it presented conditions for tropical transition; however a decrease of latent heat fluxes and an increase of vertical wind shear prevented the completion of tropical transition for Anita.

Although there has been an increase in the investigation of STCs around the world, the relative contribution of baroclinic and diabatic processes during their development is not yet fully understood, particularly over the South Atlantic Ocean. Therefore, this study aims to explore Anita's development using the thermodynamic and vorticity budget equations. We also analyze the associations between the spatial patterns of the residual fields of both budgets over Anita to verify how convection relates with the vorticity tendencies.

This paper is organized as follows. Section 2 describes the data and methodology. Section 3 presents Anita's track, Cyclone Phase Space (CPS; Hart 2003) analysis, synoptic discussion, results of the heat and vorticity budgets and the respective associations between both residual fields. Finally, a summary and conclusions are given in section 4 .

\section{Data and methodology}

We used data from the National Centers for Environmental Prediction (NCEP) Final Analysis (FNL; National Centers for Environmental Prediction/National Weather Service/NO 2000), which correspond to the initial conditions for the NCEP Global Forecast System (GFS) global model. This data is available at a 6-hourly frequency, $1.0^{\circ}$ grid spacing and at 26 pressure levels from 1000 to $10 \mathrm{hPa}$. We also used daily SST anomaly data from the NOAA OI SST V2 High Resolution Dataset, available at a $0.25^{\circ}$ grid spacing from the NOAA/OAR/ESRL PSD website at http://www.esrl.noaa.gov/psd/.

Anita's track was identified at different atmospheric levels (925 hPa and $850 \mathrm{hPa}$ ) using an algorithm developed by Sugahara (2000) and later modified by Reboita et al. (2010), in which cyclones are identified through cyclonic relative vorticity maxima. The track was also obtained through visual inspection of mean sea level pressure (MSLP) fields to validate the relative vorticity 
tracks and verify if both methods are appropriate to identify this type of rare cyclone.

The tracking results (latitude and longitude at each timestep) were given as inputs for the CPS* algorithm, along with surface temperature, and geopotential height and wind fields on pressure levels. CPS computes three parameters to infer the cyclone's nature (tropical, extratropical or hybrid): 1) thermal or thickness asymmetry $(B), 2)$ lower-tropospheric thermal wind $\left(-V_{T}^{L}\right)$, and 3) upper-tropospheric thermal wind $\left(-V_{T}^{U}\right)$. The evaluation of the three-dimensional structure of the cyclones as given by these parameters can also identify transitioning processes occurring throughout their life cycle. The thermal wind parameters are a measure of the vertical change in geopotential height gradients, whilst B measures the 900-600 hPa thickness difference between sides of a bisected $500 \mathrm{~km}$-radius circle, centered on the cyclone. The CPS graphical output includes $B$ versus $-V_{T}^{L}$ and $-V_{T}^{U}$ versus $-V_{T}^{L}$. More information about this algorithm is given in Hart (2003).

The synoptic, dynamic and thermodynamic aspects of Anita were then explored. Cloud patterns were discussed using satellite imagery obtained from the group responsible for tropical cyclone products from the NRL, and GOES-12 satellite imagery (sourced from CPTEC-INPE 2013). The GOES-12 imagery were overlaid with $200 \mathrm{hPa}$ streamlines from FNL to highlight relationships between distributions of cloud patterns and the upper level cyclone structure.

The heat and vorticity budgets in equations 1 and 2 , espectively, were computed for all vertical pressure levels and timesteps (every 6 hours). All terms involving spatial (x, y and coordinates) and temporal (time) derivatives on the right side of the equations 1 and 2 were calculated using centered finite differences, while the terms on the left side were obtained as residuals of each equation.

$$
F_{T}=\frac{\partial T}{\partial t}-\left(-\vec{V}_{H} \cdot \vec{\nabla}_{p} T+\omega \frac{R T}{c_{p} p}-\omega \frac{\partial T}{\partial p}\right)
$$

$F_{\zeta}=\frac{\partial \zeta}{\partial t}-\left[-\vec{V}_{H} \cdot \vec{\nabla}_{p} \zeta-\omega \frac{\partial \zeta}{\partial p}-v \beta-(\zeta+f) \vec{\nabla}_{p} \cdot \vec{V}_{H}+\left(\frac{\partial \omega}{\partial y} \frac{\partial u}{\partial p}-\frac{\partial \omega}{\text { to }}-\frac{\partial v}{\partial x} \frac{\partial}{\partial \phi}\right)^{\text {the }}\right.$ hity advection, vertical relative vorticity advection, where $T$ is temperature, $\vec{V}_{H}$ represents the horizontal wind, $\omega$ is the pressure vertical velocity, $p$ is the atmospheric pressure, $R$ is the gas constant $\left(287 \mathrm{~J} \mathrm{~K}^{-1} \mathrm{~kg}^{-1}\right), c_{p}$ is the specific heat at constant pressure $\left(1004 \mathrm{~J} \mathrm{~K}^{-1} \mathrm{~kg}^{-1}\right), \zeta$ is relative vorticity, $f$ is planetary vorticity, $\beta$ is the meridional change of planetary vorticity and $F_{T}$ and $F_{\zeta}$ denote the heat and vorticity budget residuals, respectively. Note that both $F_{T}$ and $F_{\zeta}$ also include the effects of computational and observational uncertainties (Sinclair 1993) and hence the residuals should be interpreted with caution.

In equation 1, the left side represents the residual or diabatic term, which includes processes associated with water vapor in the atmosphere, radiative and sensible fluxes (Dutton 1986). The vertical profile of this residual allows the interpretation of which of these physical processes is most important. According to Carlson (1991), the sensible heat flux maximizes near the surface (Iwabe and da Rocha 2009), while shallow and deep convections show a maximum heating, respectively, in the middle and upper troposphere. In these last two cases, the upward motion maxima tend to occur slightly below the levels of maximum heating (Carlson 1991).

The right side terms in equation 1 correspond to (from left to right) the local temperature tendency, horizontal temperature advection, adiabatic expansion/compression and vertical temperature advection. We also compute the sum (hereafter $S_{w}$ ) of the adiabatic term and the vertical temperature advection to quantify the local temperature tendencies due to the vertical motion processes.

The term on the left side of equation 2 refers to the residue of the vorticity budget, which represents apparent sources or sinks of vorticity in the atmosphere. As described in the literature (e.g. Reed and Johnson 1974; Chu et al. 1981), regions with signicant convective activity show an apparent source of cyclonic vorticity in the upper troposphere and an apparent sink near the surface, suggesting a vertical transport of vorticity by convective processes.

The right side terms of equation 2 represent (from left meridional advection of planetary vorticity, the divergence or 
Thermodynamic and dynamic processes were accordingly explored by daily vertical profiles averaged over a $10^{\circ} \times 10^{\circ}$ box centered on the surface low and by spatial pattern analyses at different pressure levels. The vertical profiles were first averaged over the box for each timestep and location and then computed as daily averages (from 00 UTC to 18 UTC) for each stage of Anita (see caption of Fig. 1b for further explanation). The methodology used here to compute the averaged vertical profiles centered on the surface low, i.e. moving with Anita's trajectory, is similar to the one of Morrison and Businger (2001). These authors analyzed the main terms of the vorticity tendency equation through vertical profiles averaged over a $275 \mathrm{~km}$ radius surrounding the center of a surface Kona low. Sinclair (1993) and Sinclair and Revell (2000) also calculated vertical profiles of the vorticity and thermodynamic budget terms for cyclones, however these authors used a quasi-Lagrangian framework moving with the translation velocity of the cyclone.

\section{Results}

\subsection{Cyclone track and Cyclone Phase Space}

Cyclone Anita had a life cycle of almost 10 days, as defined by MSLP, in early March 2010 (Fig. 1). The long-lasting cyclone developed at subtropical latitudes, around $19^{\circ} \mathrm{S}-37^{\circ} \mathrm{W}$, and later moved to the southwest until it reached the vicinity of Brazil's south coast $\left(\sim 30^{\circ} \mathrm{S}-47^{\circ} \mathrm{W}\right)$, where it stayed quasi-stationary for about 2 days. It then turned, moving southeast and merging with an extratropical cyclone. Fig. 1a shows Anita's tracks as a function of MSLP and relative vorticity at $925 \mathrm{hPa}$ and $850 \mathrm{hPa}$. The vorticity derived tracks begin later than the MSLP track, indicating that the surface low pressure center developed prior to the cyclonic circulation at low levels. The relative vorticity tracks are slightly displaced to east compared to the MSLP track and all trajectories are in reasonable accordance with each other. Fig. 1a also shows that Anita developed in a region of positive SST anomalies which extended southwest along the Brazilian coast. By the end of its life cycle, however, Anita moved towards extratropical latitudes with negative SST anomalies.

The temporal evolution of MSLP intensity of Anita is displayed in Fig. 1b. It is noteworthy that the MSLP intensity attains its lowest value at the end of Anita's life cycle. Such deepening happens when Anita is moving towards higher latitudes and transitioning to an extratropical cyclone. Also of note is the representation of a weakening stage, prior to this deepening phase.

According to the cyclone track, five timesteps were selected to illustrate the most significant aspects of Anita's evolution (see cross marks and annotations in Fig. 1b). The incipient stage (1200 UTC, 4th) is defined as the point at which the central MSLP begins to decrease; during the intensifying stage (1200 UTC, 7th) the low pressure system starts moving southwest. The time at which the system reaches the lowest MSLP (1004.5 hPa) whilst in its subtropical phase is labeled as the mature stage (1200 UTC, 9th). The weakening stage (1200 UTC, 10th) is marked by a slightly increase in the central pressure, and during extratropical transition (1200 UTC, 11th) there is a second, steeper, deepening of the surface cyclone.

According to the Cyclone Phase Space diagrams (Fig. 2), Anita developed initially as a subtropical cyclone, with a warm core at low levels $\left(-V_{T}^{L}>0\right)$ and a cold core at upper levels $\left(-V_{T}^{U}<0\right)$. This hybrid structure was maintained until 0600 UTC on the 10th, i.e., between the mature and the weakening stages (Fig. 2b). During this period, the $B$ parameter (Fig. 2a) is below $15 \mathrm{~m}$, which indicates that the cyclone had a symmetric and non-frontal structure. Starting from 0600 UTC on the 11th, 6 hours prior to the extratropical transition stage, $B$ begins to grow as $-V_{T}^{L}$ decreases, indicating that the cyclone structure was turning asymmetric as its low level core cooled and representing Anita's extratropical transition. The mean radius of $925 \mathrm{hPa}$ gale force wind increases during extratropical transition, as the cyclone's central MSLP deepens. This second phase of intensification by the end of Anita's life cycle is a result of the merging process occurring between Anita and another extratropical cyclone that was moving eastward at higher latitudes. The upper level core also starts cooling at a maximum rate from $0000 \mathrm{UTC}$ on the 12 th (Fig. 2b).

\subsection{Synoptic analysis}

\subsubsection{Spatial fields}

Anita's cyclogenesis occurred in a region of pre-existing cyclonic circulation, where a prior cyclone developed one day earlier 
(a)

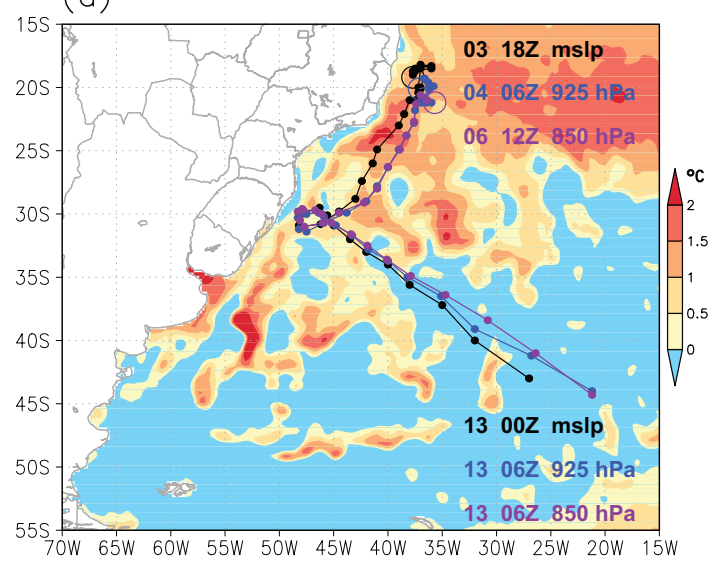

(b)

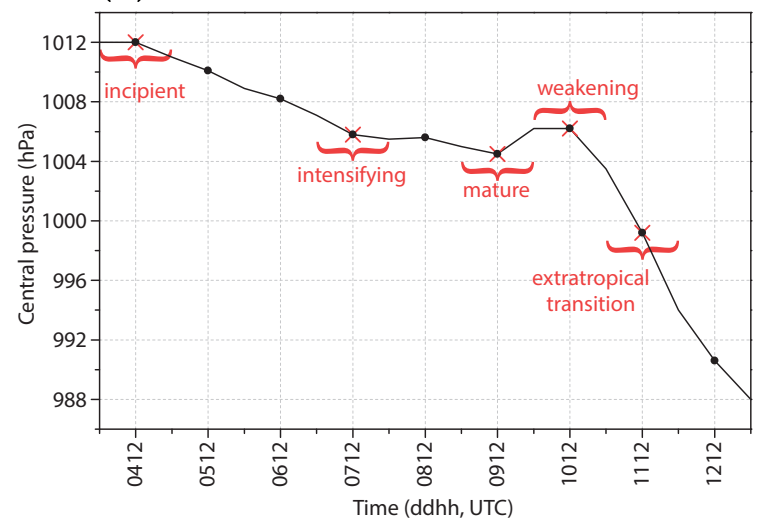

Figure 1. (a) Sea surface temperature anomaly (relative to the 1971-2000 climatological mean) averaged from 3 to 13 March 2010 (shaded, ${ }^{\circ} \mathrm{C}$ ) and Anita's track (every 6 hours) as a function of MSLP (black) and relative vorticity at $925 \mathrm{hPa}$ (blue) and at $850 \mathrm{hPa}$ (red); the first track of each trajectory is identified by a circle, and the first and second two numbers indicate the day and hour (in UTC time for March 2010) of the first and last tracks. (b) Central MSLP (hPa) temporal evolution of Anita, where dd and hh stand for day and hour (in UTC time for March 2010); each stage of the cyclones life cycle is labeled and marked on the plot. The red crosses indicate the timestep of each stage used for the synoptic fields of Figs. 3-5, while the red curly brackets indicate each full day (from 00UTC to 18UTC) of each stage used for the daily averages of Fig. $7 \mathrm{a}$ and Figs. 8-11.

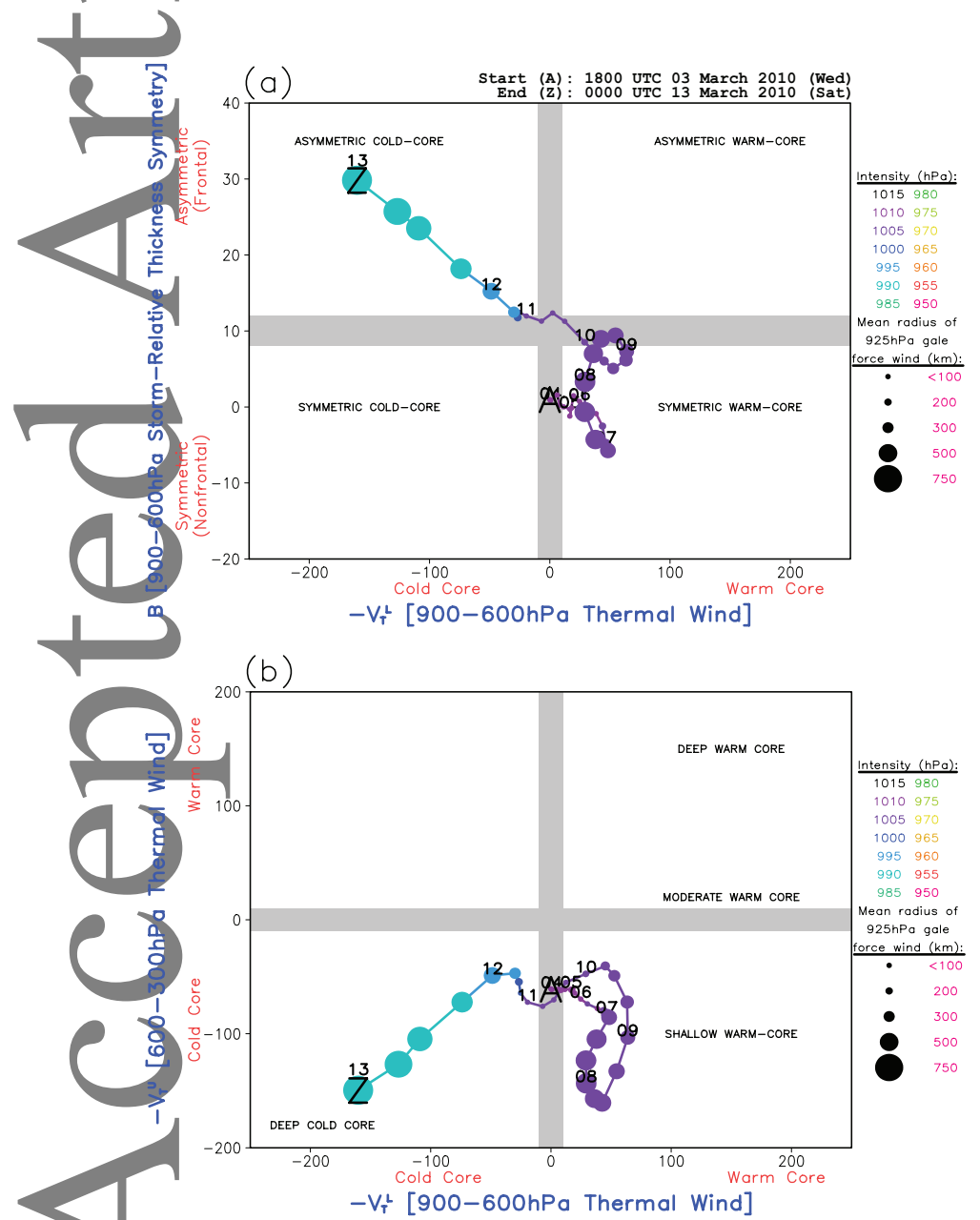

Figure 2. Cyclone Phase Space diagrams for Anita using 1 degree FNL data every 6 hours: (a) $-V_{T}^{L}$ vs $B$ and (b) $-V_{T}^{L}$ vs $-V_{T}^{U}$. A indicates the beginning (1800 UTC 03 March 2010) of the plotted life cycle and Z indicates the end (0000 UTC 13 March 2010). A marker is placed every 6 hours, where the shading indicates the cyclone MSLP intensity and the size indicates the relative size of the $925 \mathrm{hPa}$ gale force $\left(>17 \mathrm{~m} \mathrm{~s}^{-1}\right)$ wind field, according to the legend on the right of each plot. More information about the Cyclone Phase Space is given in Hart (2003).

and later moved southeast (not shown). In the incipient stage (1200 UTC of the 4th; Figs. 3a, 4a and 5a), a closed isobar of $1012 \mathrm{hPa}$ corresponding to Anita is around $19^{\circ} \mathrm{S}-37^{\circ} \mathrm{W}$, with an inverted pressure trough (located north of the broad anticyclonic circulation over the Atlantic) extending southwest. At this time, even though the closed isobar associated with Anita is small, there is already an associated cyclonic vorticity core at low levels characterizing the cyclone formation (Fig. 3a). The low level horizontal temperature advection is weak over Anita at this stage, however there is some moisture flux convergence at $925 \mathrm{hPa}$ over the area, which extends southwest over the inverted pressure trough axis (Fig. 5a). At upper levels, there is a shallow and short wave trough around $22^{\circ} \mathrm{S}-43^{\circ} \mathrm{W}$, and the streamlines in Fig. 4a show a diffluent flow relative to the downstream trough axis, which causes divergence aloft (fig. not shown) and contributes to enhance the upward motions throughout the atmospheric column (see Fig. 7a for the incipient stage), consequently reinforcing the low pressure core and enhancing convergence at low levels. At $500 \mathrm{hPa}$ the geopotential height field does not show any trough associated with Anita's development. There is, however, a large circular-shaped cold top cloud producing precipitation over the area and surroundings of the surface low.

In the incipient stage over the South Pacific ocean and near the west coast of South America (not shown) there is a shortwave trough at the upper troposphere, which travels eastward towards the South Atlantic ocean. This trough amplifies in a north-south direction as it approaches the east coast of South America, and around 1800 UTC of the 6th (not shown) the inner part of the trough starts to detach from the meridional stream. This detachment, centered around $25^{\circ} \mathrm{S}-50^{\circ} \mathrm{W}$, characterizes the start of the tear-off stage of the upper level low which will soon merge 
(a) Incipient

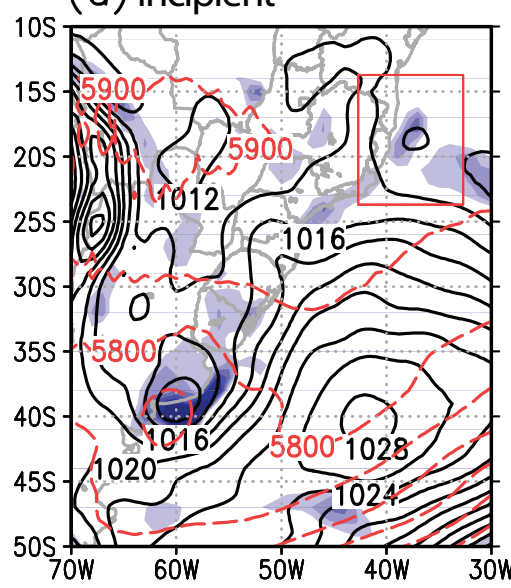

(d) Weakening

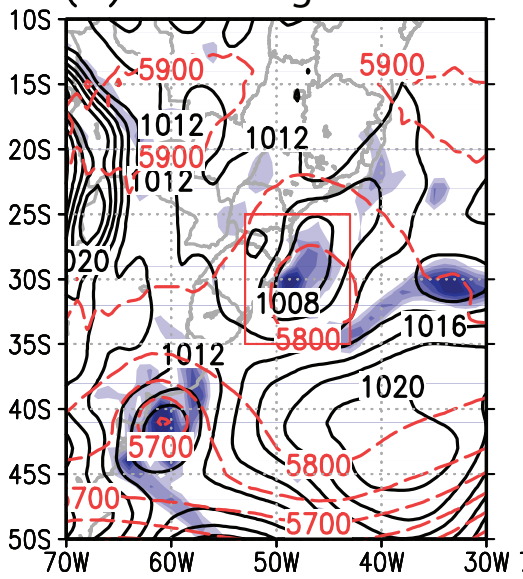

(b) Intensifying

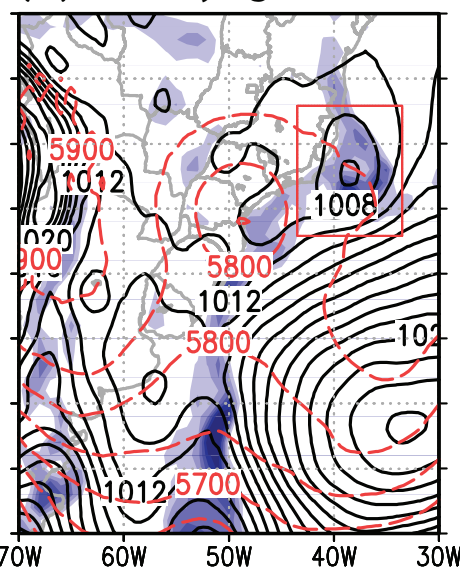

(e) Extratropical transition

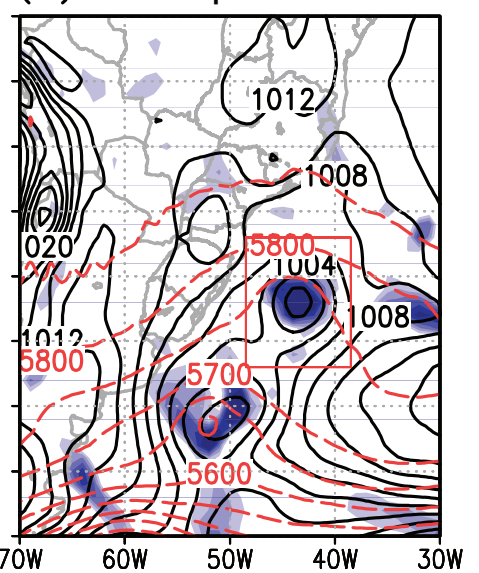

(c) Mature
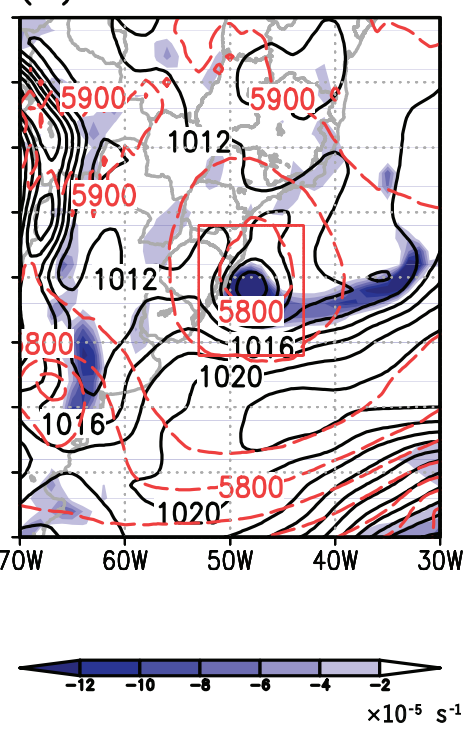

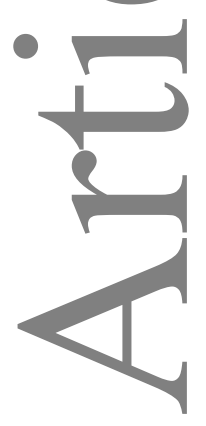

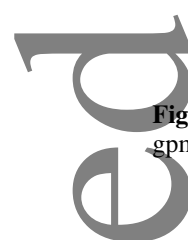

$+1$

with the lower level counterpart of Anita. By the intensifying stage (1200 UTC of the 7th; Figs. 3b, $4 b$ and $5 b)$, this tearoff can be seen as an omega shape form in the $500 \mathrm{hPa}$ geopotential height contours and in the $200 \mathrm{hPa}$ streamlines. $200 \mathrm{hPa}$, there is diffluence occuring at the trough exit and Over Anita (Fig. 4b), which causes divergence aloft (not shown) and contributes to further increase the rising motion over Anita (see Fig. 7a). Dynamical support is also provided by the vertical alignment of the trough exit at upper levels, leading to cyclonic vorticity advection increasing with height (see Fig. 9c), causing strong rising motion at mid levels (see Fig. 7a) and low level convergence, consequently deepening the surface low. The low pressure core of Anita intensifies to about $1006 \mathrm{hPa}$ and starts to move southwestward and merge with the upper level low. By this stage, Anita's MSLP core is centered around $22.5^{\circ} \mathrm{S}-38^{\circ} \mathrm{W}$ and the inverted pressure trough is now broader and extends farther south, around $25^{\circ} \mathrm{S}-50^{\circ} \mathrm{W}$. Low level warm air advection and low level moisture flux convergence occur along the stalled pressure trough near the Brazilian coast and over an area of increased low level cyclonic relative vorticity associated with Anita, northwest of the wide anticyclonic circulation over the Atlantic. Two main synoptic-scale cloud bands associated with great values of accumulated rainfall are seen along Brazil's coast. The northernmost band is located northeast of Anita's core $\left(22^{\circ} \mathrm{S}-35^{\circ} \mathrm{W}\right)$ and has cold cloud tops with temperatures below $-70^{\circ} \mathrm{C}$ (Fig. 4b). These cold cloud tops indicate deeper convection over the cyclonic convergence area, further enhanced by low levels northerly winds that contribute to warm air advection over the surface low. The second main synoptic-scale cloud band has top temperatures between $-50^{\circ} \mathrm{C}$ and $-70^{\circ} \mathrm{C}$ and is located east of the upper level low.

Development continues, and around 1700 UTC of the 8th (Fig. 6a), Anita is located around $29^{\circ} \mathrm{S}-43^{\circ} \mathrm{W}$, which indicates a displacement of 7 degrees to the south and 14.5 degrees to the west in 30 hours. At this time, most of the cloud bands are observed in the southern portion of the cyclonic circulation, stretching along 
(a) Incipient

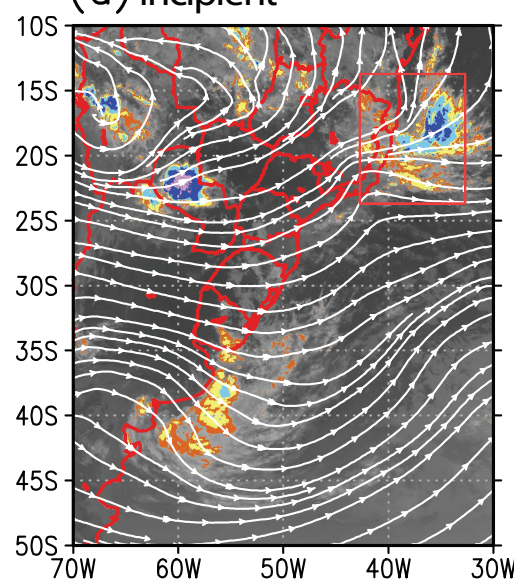

(d) Weakening

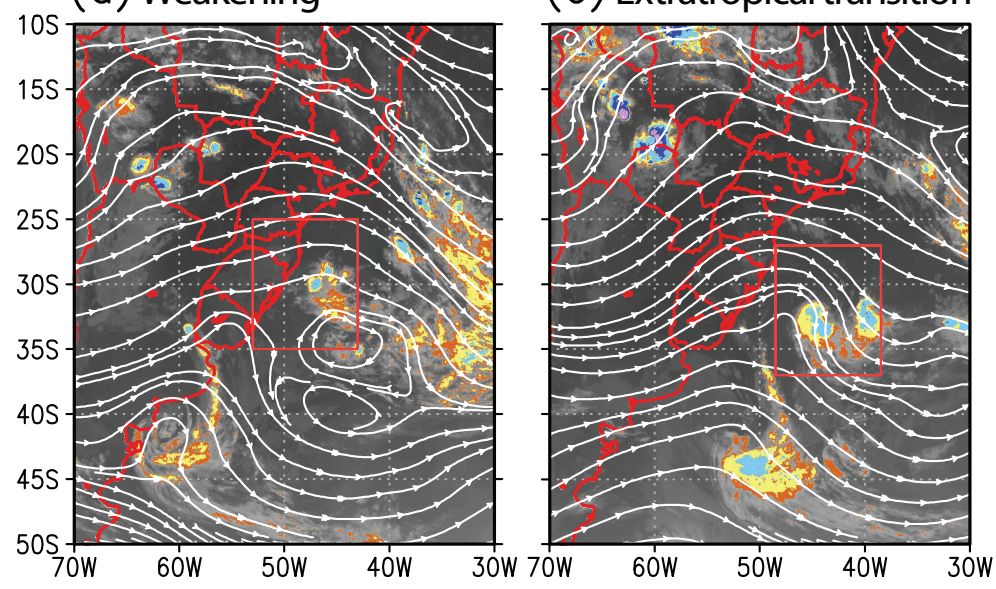

(c) Mature

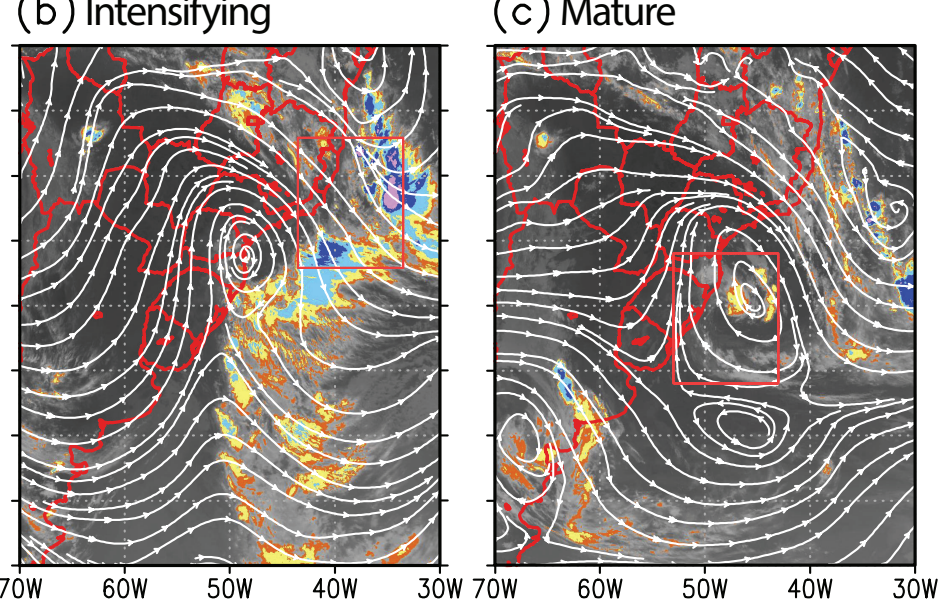

(e) Extratropical transition

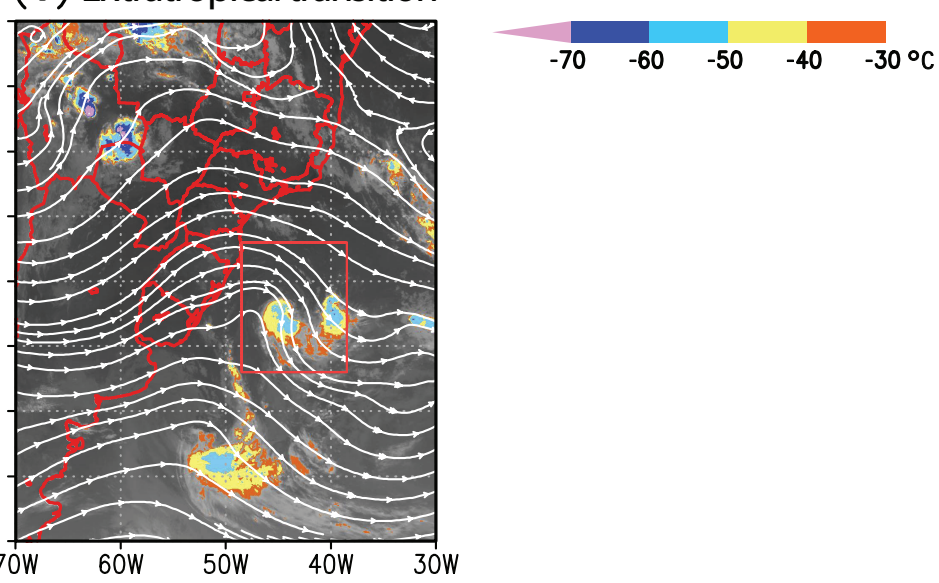

Figure 4. GOES-12 imagery overlaid with $200 \mathrm{hPa}$ streamlines for (a) incipient, (b) intensifying, (c) mature, (d) weakening and (e) extratropical transition. The colored shading represents colder cloud-top temperatures $\left({ }^{\circ} \mathrm{C}\right)$, while the grey-shading represents either warmer cloud-top temperatures or the Earth's surface temperature. In each plot, the $10^{\circ} \times 10^{\circ}$ degree box is centered on the surface low.

1

$231^{\circ} \mathrm{S}$ and producing a considerable amount of precipitation over

Southern Brazil and surrounding oceanic areas.

After 48 hours, in the mature stage (1200 UTC of the 9th; Figs. 3c, 4c and 5c), Anita reaches an equivalent barotropic

Stage with vertical alignment of the low pressure core throughout the depth of the troposphere. The system is positioned around $31^{\circ} \mathrm{S}-48^{\circ} \mathrm{W}$ with a MSLP of $1005 \mathrm{hPa}$. Intense winds at low leyels flow towards land as part of the cyclonic circulation of Anita, in particular over Uruguay and the southernmost region of/Brazil, being associated with moisture flux convergence at the lower troposphere. The upper counterpart of Anita is completely detached from the main stream, forming a well-developed closed circulation or cut-off low in both mid- and upper- levels. At $200 \mathrm{hPa}$, the strong forward-falling ridge upstream from the upper level low has also separated from the main stream, forming a closed anticylonic circulation south of Anita's cut-off low.

These two centers of closed circulation form a north-south dipole pattern, which remains quasi-stationary (or with slow propagation) for 24 hours and prevents the earlier displacement of Anita's upper level low counterpart. The upper level westerly jet cannot penetrate the dipole pattern region and thus the most intense flow shifts to the north and to the south of the dipole pattern system. According to Dias Pinto et al. (2013), the configuration of this pattern contributed to reduce the vertical wind shear over Anita, which is one of the main ingredients to favor tropical development. Over Anita, intense rainfall of up to $100 \mathrm{~mm} \mathrm{day}{ }^{-1}$ (not shown) occurs in the core of a circular region of precipitation. Two main bands with cloudtop temperatures between $-40^{\circ} \mathrm{C}$ and $-50^{\circ} \mathrm{C}$ and other warmer clouds are organized in a spiral shape over the ocean (along $30^{\circ} \mathrm{S}$ ) and coastal regions over South Brazil. The spiral shape is better seen in Fig. 6b, with the visible satellite imagery almost 6 hours after the mature stage. In this figure, the bottom left portion (to the left of the yellow line) shows the clouds organized in a Cshape, in association with the upper level diffluent flow and the dipole pattern (Fig. 4c), while the clouds on the center of the figure 
(a) Incipient

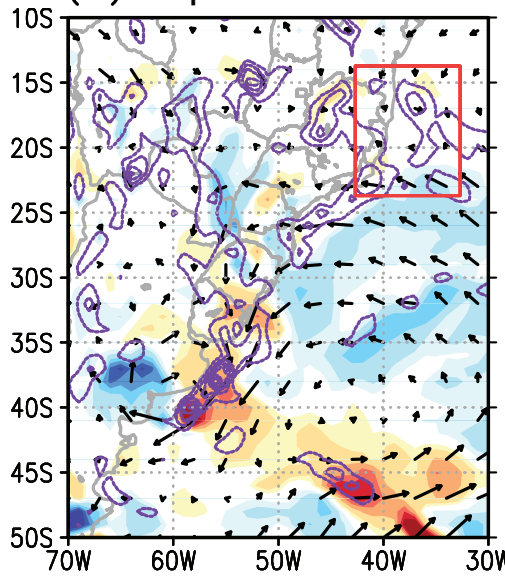

(d) Weakening

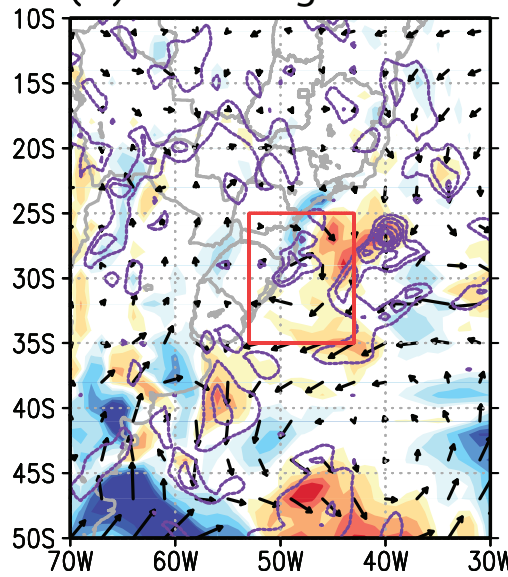

(b) Intensifying

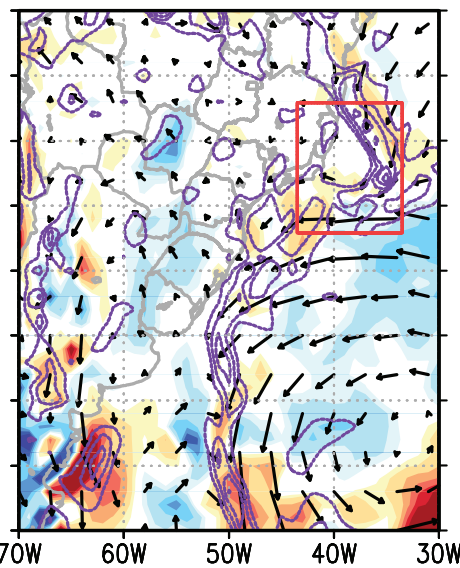

(e) Extratropical transition

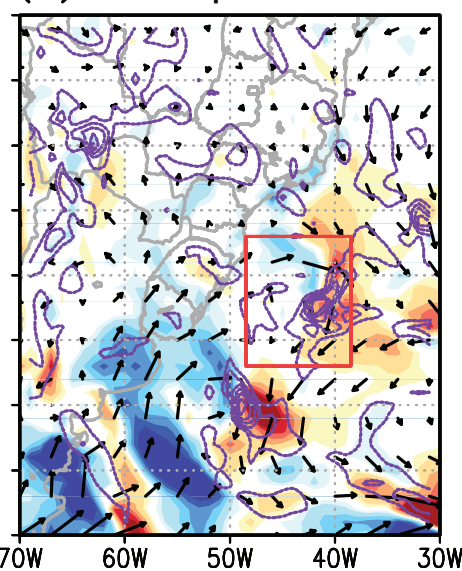

(c) Mature
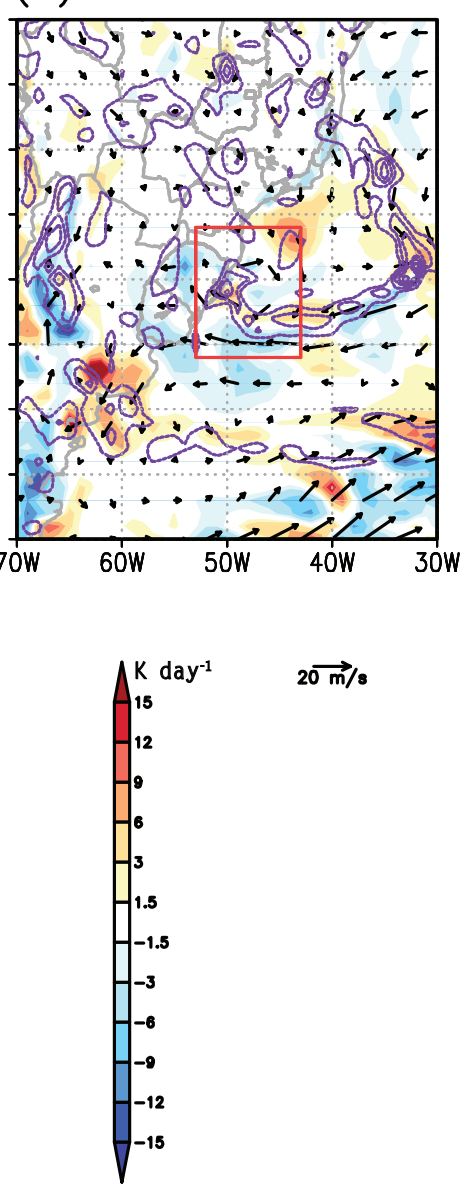

$20 \overrightarrow{\mathrm{m}} / \mathrm{s}$
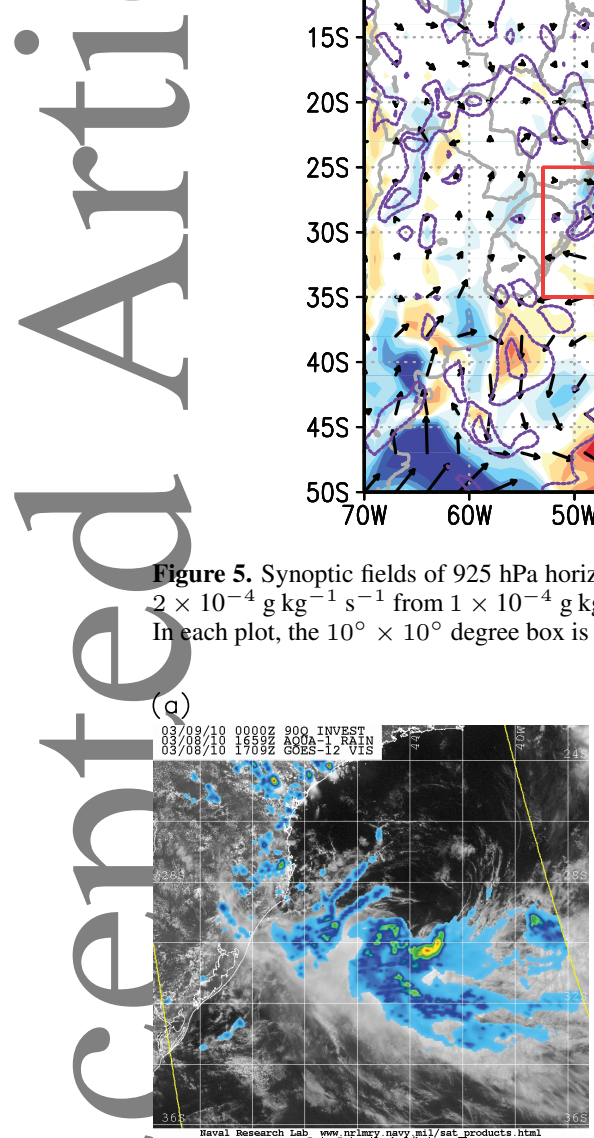

(b)

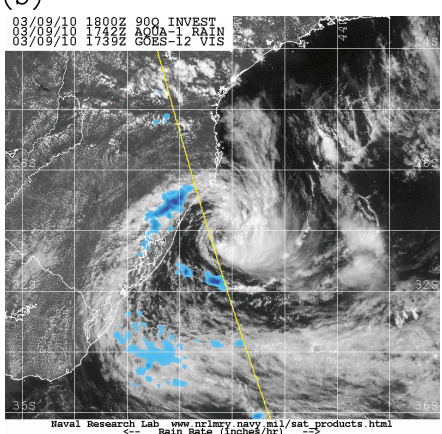

(c)

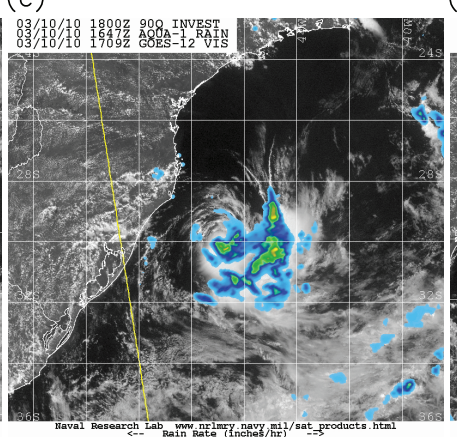

(d)

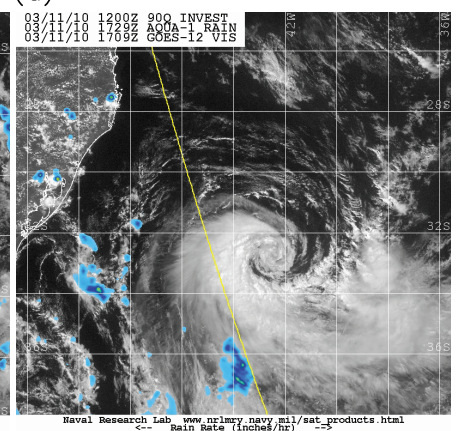

Figure 6. AQUA-1 rain rate (colored shaded with swath edges marked by yellow lines, inches/hr) and GOES-12 visible imagery (black and white shaded) for (a) 1709 UTC 08 March, (b) 1739 UTC 09 March, (c) 1709 UTC 10 March and (d) 1709 UTC 11 March 2010. Imagery were obtained from the NRL group in November 2010.

(mostly to the right of the yellow line) have a more spiral-shape pattern, in association to the low pressure core of Anita. Over the center of the surface low, around $31^{\circ} \mathrm{S}-48^{\circ} \mathrm{W}$, there is a cloud free area resembling the eye structure of tropical cyclones.

In the following hours, however, the convection arising within the core of Anita contributes to weaken the upper level low. Thus, by the weakening stage (1200 UTC of the 10th; Figs. 3d, 4d and $5 \mathrm{~d})$, the upper level dipole pattern is still prominent but weaker. The upper level low shows a smaller amplitude in the streamlines and its core is displaced southeast compared to the previous stage.

The anticyclonic circulation, however, remains almost stationary to the south, preventing the upper level cyclone from moving further towards higher latitudes. Note that, by this stage, Anita has an eastward vertical inclination. Also of note is that there is a large trough in the main stream approaching from the rear of Anita's cut-off low in $200 \mathrm{hPa}$, which contributes to weaken the dipole pattern. The cut-off low at middle levels also begins to lose intensity, as well as the MSLP core which weakens to $1006 \mathrm{hPa}$. 
Like its upper counterpart, the surface cyclonic core remains quasi-stationary compared to the prior stage, retrogressing one degree to the north. Even though the low level warm air advection over Anita is intense, the low level moisture flux convergence is decreased. The clouds still produce heavy precipitation and are organized in a closed-circle shape, and the eye over the center of the storm is dissipated as shown in Fig. 6c. Also of note is that another cyclone has developed over eastern Argentina ( $\sim 41^{\circ} \mathrm{S}-60^{\circ} \mathrm{W}$, Fig. 3d).

In the following hours, the upper level dipole pattern begins to merge with the main stream, characterizing the final stage of Anita's upper level low. By the extratropical transition stage (1200 UTC of the 11th, Figs. 3e, 4e and 5e), the upper level dipole pattern finally dissipates and only a trough is seen in the $200 \mathrm{hPa}$ streamlines. Just like the incipient and the intensifying stage, during the extratropical transition stage diffluence occurs at $200 \mathrm{hPa}$ over the surface low, leading to divergence aloft (not shown) and contributing to increase vertical motions (see Filg. 7a). The cut-off low at $500 \mathrm{hPa}$ also dissipates and its remaining trough shifts to the southeast and begins to merge with the trough of another cyclonic system located to the south. This atmospheric structure in upper and middle levels contributes to the southeastward motion of the surface low, which also merges With the low level counterpart of the cyclone located to the south. During this process, Anita undergoes extratropical transition and deepens at a maximum rate. Moisture flux convergence at the low troposphere increases again, associated with intense low level warm air advection east of Anita's core. Two large-scale cloud bands with cloud-tops below $-50^{\circ} \mathrm{C}$ develop east of the upper level trough as lower level winds and convergence increase. The precipitation field retains its circular shape and its core intensifies to around $150 \mathrm{~mm} \mathrm{day}^{-1}$ (not shown); the rainfall affects only oceanic areas however. The visible satellite image on this day (Fig. 6d) shows Anita displaced far from the coast.

\subsubsection{Vertical profiles}

Fig. 7a shows vertical profiles of the pressure vertical velocity (or omega) averaged over a $10^{\circ} \times 10^{\circ}$ box centered on the surface low and Fig. $7 \mathrm{~b}$ shows the maximum wind speed intensity occurring within this box. Fig. 7a shows that the greatest upward motions occur during the incipient and the intensifying stages, with the intensifying stage being characterized by intense convection, as shown in Fig. 4b. Upward motions decrease substantially during the mature and weakening phases of Anita, with the weakening stage showing upward motion from the surface to $600 \mathrm{hPa}$ and weak downward motion aloft. During extratropical transition, however, upward motions begin to increase again throughout the troposphere.

During Anita's hybrid stage, i.e, from incipient until 0600 UTC of the 11th, winds decrease with height from the surface up to about $600 \mathrm{hPa}$ and then increase with height up to the upper troposphere (Fig. 7b). During extratropical transition, however, the wind intensity increases with height throughout the troposphere. These wind speed profiles are consistent with the thermal wind arguments used in CPS to classify the nature of cyclones. Guishard et al. (2007) describes a subtropical storm occurred in the North Atlantic in May 2001 with a wind profile similar to that of Anita during its hybrid stage. Between the 7th and 9th, when Anita is approaching the south coast of Brazil, maximum winds increase throughout the atmospheric column and, at $925 \mathrm{hPa}$, peak values of $\sim 30 \mathrm{~m} \mathrm{~s}^{-1}$ occur between 0000 UTC of the 8th and 9th. Strong near surface winds over oceanic areas can generate high sea waves and sink boats (Gozzo and da Rocha 2013; da Rocha et al. 2004). Prior to that, from genesis until 1200 UTC of the 6th, low level maximum winds remained moderate, between 10 and $15 \mathrm{~m} \mathrm{~s}^{-1}$. The weakening of wind speeds throughout the depth of the troposphere that occurs after the mature stage, but before extratropical transition, is consistent with the increase of MSLP shown in Fig. $1 \mathrm{~b}$ and is also consistent with a decrease of maximum cyclonic vorticity in the whole atmospheric column (not shown).

\subsection{Heat budget}

Fig. 8 presents the vertical profiles of the heat budget terms averaged over a box centered on the surface low for each stage of Anita's life cycle (as indicated by the red curly brackets in Fig. 1b). For the local temperature tendencies, Fig. 8a shows values around zero (or slightly negative) throughout the troposphere in the incipient stage. At low levels (1000-850 hPa) there is a warming tendency which increases from the intensifying 
(a)

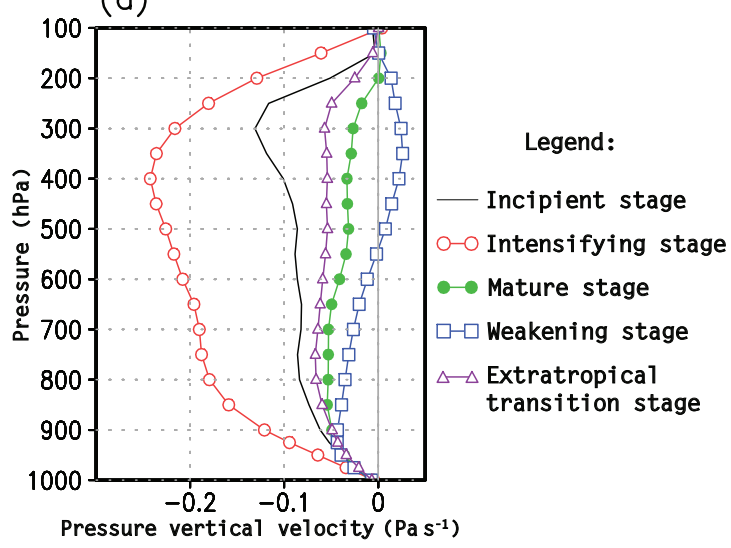

(b)

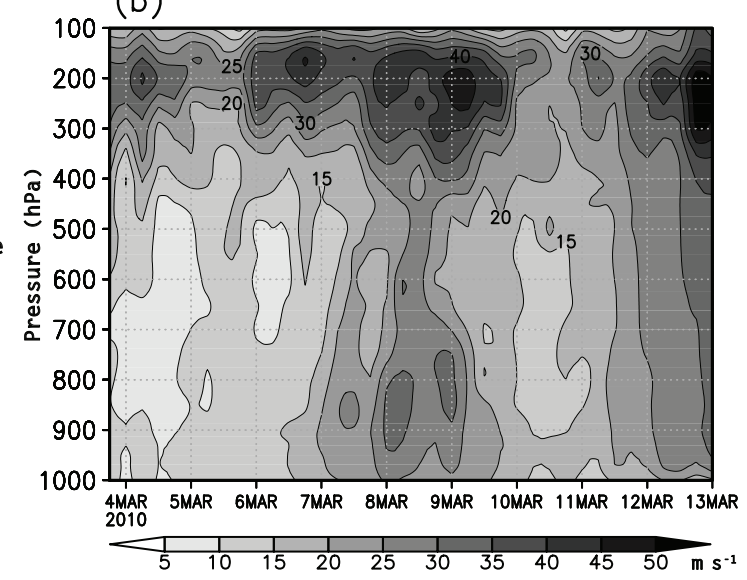

Figure 7. (a) Vertical profiles of pressure vertical velocity $\left(\mathrm{Pa} \mathrm{s}^{-1}\right.$ ) averaged over a $10^{\circ} \times 10^{\circ}$ degree box centered on the surface low, for: incipient (black with no symbol), intensifying (red open circle), mature (green closed circle), weakening (blue open square), and extratropical transition (purple open triangle) stages. (b) Maximum wind speed $\left(\mathrm{m} \mathrm{s}^{-1}\right)$ occurring within the same $10^{\circ} \times 10^{\circ}$ degree box, for all available FNL pressure levels as a function of time. In Fig. $7 \mathrm{a}$, the vertical profiles were calculated as daily averages (from 00 UTC to 18 UTC) for each stage of Anita, as indicated by the red curly brackets in Fig. 1b.

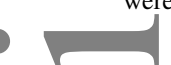

to the mature stage and then decreases slightly during the weakening stage. By the extratropical transition stage, however, there is a cooling tendency at lower levels of the troposphere. At upper levels (between $500 \mathrm{hPa}$ and $200 \mathrm{hPa}$ ), the biggest warming tendencies occur during the intensifying stage. Note that only the intensifying stage presents positive tendencies throughout the troposphere below $150 \mathrm{hPa}$. The biggest cooling tendencies upper levels (between $450 \mathrm{hPa}$ and $300 \mathrm{hPa}$ ) occur in the extratropical transition stage followed by the mature stage.

\section{I}

Vertical profiles of horizontal temperature advection (Fig. 8b) show that the intensifying and the extratropical transition stages present the greatest upper level warm air advection, which is accordance with the results of Rolfson and Smith (1996), where the authors verified that the value of the upper level warm air advection maximum increases with the intensification of surface extratropical cyclones. These maxima of upper level warm air advection occur due to a warm layer in the upper level trough upstream of the surface cyclone (not shown). Previous studies have shown that warm air advection maxima at upper atmospheric levels are a typical feature of extratropical cyclone development (Hirschberg and Fritsch 1991; Lupo et al. 1992; Rolfson and Smith 1996). From a quasi-geostrophic perspective, warm advection increasing with the height does not contribute to cyclone development. However, some studies point out that warm advection in the upper troposphere may contribute to lower the pressure due to the atmosphere column heating (Hirschberg and Fritsch 1991). At the lower troposphere (below
$900 \mathrm{hPa}$ ), the averaged temperature advection is around zero during the incipient and intensifying stages, negative (or cold) during the mature stage and positive (or warm) during the weakening and extratropical transition stages, highlighting the transition. Warm air advection maxima in the lowest levels were also found by Rolfson and Smith (1996) in composites of extratropical cyclones with moderate-to-strong rates of surface deepening. Cold air advection (CAA) predominates from the mature to the extratropical transition stages from $500 \mathrm{hPa}$ to $250 \mathrm{hPa}$.

The large warm air advection during the intensifying stage above $900 \mathrm{hPa}$ (Fig. 8b) can explain part of the intense upward motions occurring at this stage (Fig. 7a). In the quasi-geostrophic omega equation, the term which includes the Laplacian of the thermal advection indicates that upward motion occurs in regions of maximum warm air advection (Trenberth 1978). Similarly, the cold air advection during the weakening stage at upper levels (Fig. 8b) likely contributes to the concurrent upper tropospheric downward motions at this stage (see Fig. 7a).

The profiles of the vertical temperature advection and adiabatic terms (Figs. 8c and d) are generally opposite in sign. This occurs because upward (downward) motions in the troposphere lead to 1) adiabatic cooling (warming) by expansion (compression) of the air parcels and to 2) warming (cooling) by positive (negative) vertical temperature advection, since the temperature generally decreases with height in the troposphere. Out of these two thermodynamic processes, for Anita subtropical cyclone, 
(a)

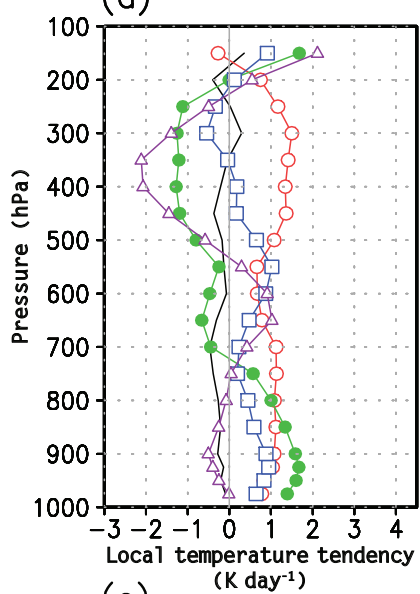

(e)

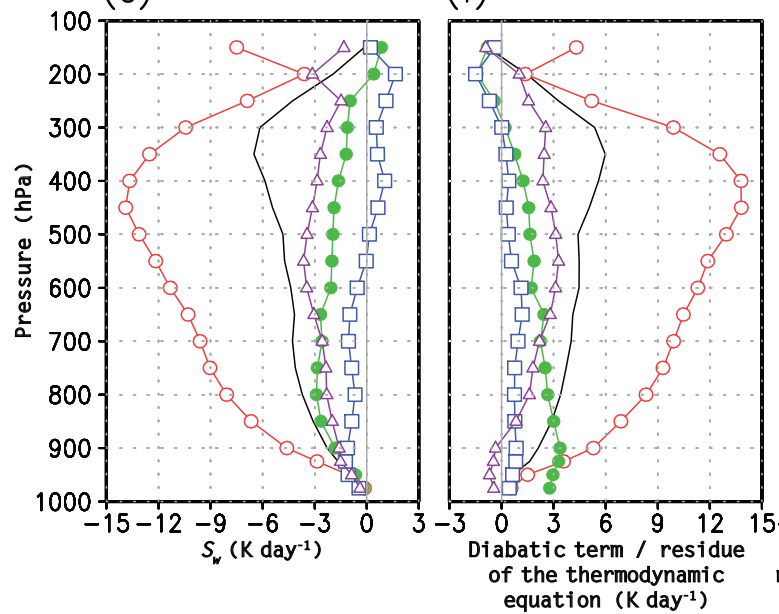

(c)

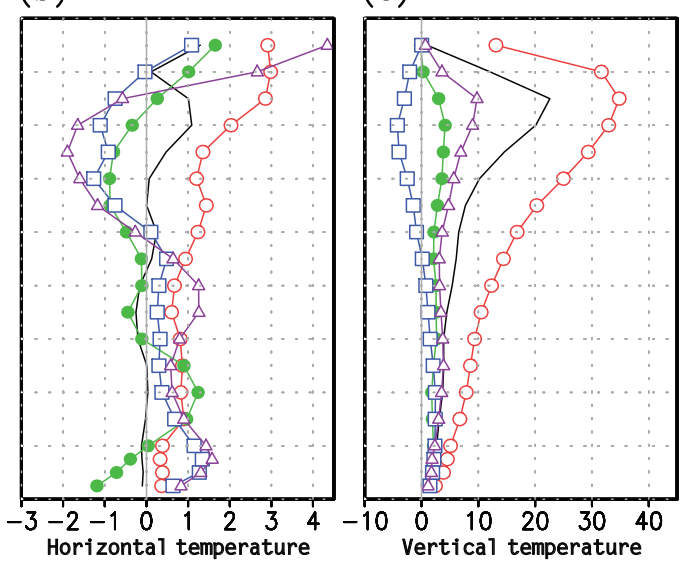

(g)

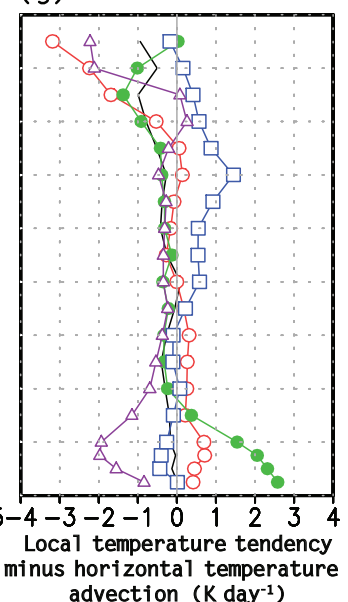

(d)

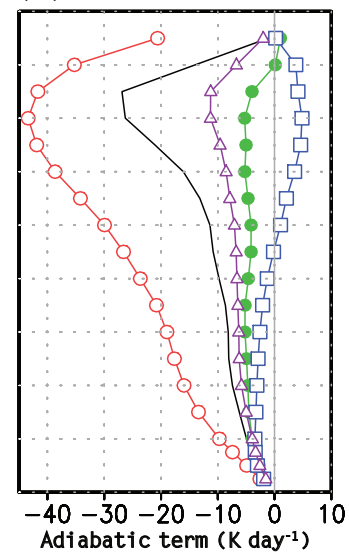

Legend:

- Incipient stage

- - Intensifying stage

- Mature stage

$\square-\square$ Weakening stage

$\Delta-\Delta$ Extratropical

transition stage

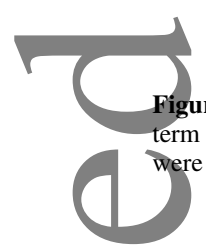

Figure 8. Vertical profiles of (a) local temperature tendency, (b) horizontal temperature advection, (c) vertical temperature advection, (d) adiabatic term, (e) $S_{w}$, (f) diabatic

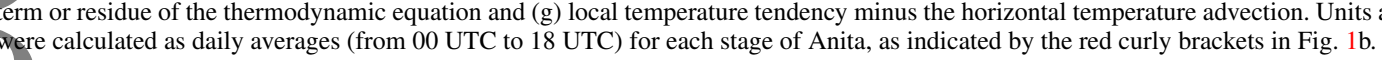

adiabatic contributions to local temperature tendencies are, with a

few exceptions, mostly greater than contributions from the vertical temperature advection, as shown in Fig. 8e (where $S_{w}$ represents the sum of the vertical temperature advection and adiabatic terms). general, below $200 \mathrm{hPa}$, the vertical profile of $S_{w}$ follows the profile of the pressure vertical velocity (Fig. 7a), indicating that adiabatic cooling (warming) predominates as a response to upward (downward) motions throughout the lifetime of Anita.

Vertical profiles of the residue of the thermodynamic equation in Fig. 8f suggest that diabatic processes act to counterbalance the temperature tendencies caused by the vertical motions mostly in middle and upper levels. This occurs since the diabatic contributions are mostly associated with water vapor phase changes in cloudy areas, evaporation of precipitation and overshooting cloud tops (da Rocha and Caetano 2010). In the lower troposphere, however, the diabatic term (Fig. 8f) does not always oppose the temperature tendencies due to $S_{w}$ (Fig. 8e). During the incipient stage, the averaged diabatic heating at low levels is small and increases by the intensifying stage, reaching maximum values by the mature stage below $975 \mathrm{hPa}$. By the weakening stage, diabatic heatic decreases at low levels and throughout the troposphere, and the extratropical transition stage is the only stage with low level diabatic cooling. Fig. $8 \mathrm{f}$ also shows that intense diabatic heating occurs throughout the troposphere above the surface low during the intensifying stage, and some diabatic cooling occurs at upper levels during the weakening stage.

The following analysis aims to identify the main mechanisms of the thermodynamic equation (Figs. 8b-f) responsible for the local temperature tendencies (Fig. 8a). Fig. $8 \mathrm{~g}$ shows the difference between the local temperature tendency (Fig. 8a) and the horizontal temperature advection (Fig. 8b). Values around zero in Fig. $8 \mathrm{~g}$ indicate that horizontal temperature advection is the main mechanism responsible for the local temperature tendencies.

This occurs mainly in the middle troposphere (between $750 \mathrm{hPa}$ and $350 \mathrm{hPa}$ ) during all stages of Anita, except the weakening 
stage. On the other hand, the larger values in Fig. 8g, which occur mainly in the lower troposphere, indicate that horizontal temperature advection is not the sole mechanism to influence the local temperature tendencies, as further discussed in the following paragraph. Also note that, during the mature and extratropical transition stages, the sign of the low level local temperature tendency (Fig. 8a) is opposite to the sign of the low level horizontal temperature advection (Fig. 8b), indicating that there are opposing mechanisms acting to cancel all temperature tendencies caused by horizontal temperature advection.

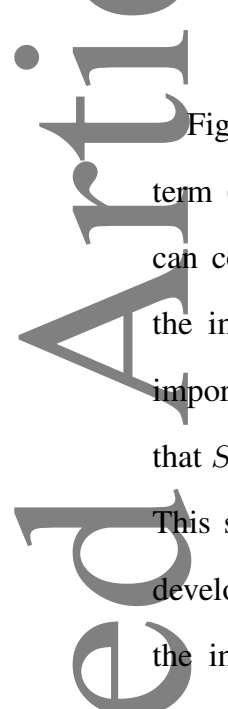

Fig. $8 \mathrm{~g}$ also represents the sum of $S_{w}$ (Fig. 8e) and the diabatic term (Fig. 8f). By analysing Fig. 8g from this perspective, we can conclude that during Anita's main subtropical phases (i.e., the intensifying and mature stages) the diabatic heating is an mlportant process at low levels, since the positive values indicate that $S_{w}$ can not counterbalance all diabatic temperature changes. This suggests that low level diabatic heating is essential to the velopment of Anita, and temperature advection (warm during plays an important role during its evolution. The large diabatic heating at low levels allows Anita to develop a hybrid temperature structure (warm core at low levels and cold core at upper levels). da Rocha and Caetano (2010) have demonstrated in a previous study the importance of diabatic heating on the numerical Simulation of a cyclone over the subtropics of the South Atlantic Ocean. Davis (2010) used idealized, moist primitive equation simulations to define subtropical cyclones in a dynamical sense and found condensation heating as the principal agent of their development. During the extratropical transition stage however, the negative values at low levels in Fig. $8 \mathrm{~g}$ indicate that diabatic cooling occurs to reinforce the negative contributions of $S_{w}$ to the local temperature tendencies, and both of these mechanisms act to cancel the low level warming tendencies caused by warm air advection (Fig. 8b). Such negative contributions of $S_{w}$ are due to adiabatic cooling at low levels, as shown in Fig. 8d. Thus, for Anita, when extratropical transition occurs, warm air advection, adiabatic cooling and diabatic cooling are the main mechanisms responsible for the local temperature tendencies at low levels.

\subsection{Vorticity budget}

Relative vorticity profiles for each phase of Anita are presented in Fig. 9a, and vertical profiles of the vorticity budget equation terms are shown in Figs. 9b-h. At the incipient stage, the cyclonic vorticity (negative values) is weak and occurs only at low levels. It then increases by the intensifying stage between the lowto middle levels. By the mature stage, cyclonic vorticity is intense and increases from the surface to the upper troposphere, with largest magnitude at $250 \mathrm{hPa}$ (Fig. 9a). Similar vertical structure evolutions are also found in extratropical cyclones due to the westward tilt with height of the low pressure core, which decreases as the system evolves (e.g. Iwabe and da Rocha 2009). For Anita, as the upper level cut-off low moves southeastward and dissipates (in the weakening and extratropical transition stages, respectively), cyclonic vorticity weakens at mid- to upper levels (Fig. 9a).

At lower levels, the local relative vorticity tendency profile (Fig. 9b) shows that the cyclonic vorticity increases from the incipient to the mature stage. By the weakening stage this pattern of continuous growth of the cyclonic vorticity stalls but is then followed by a further increase during the extratropical transition stage. At mid- and upper- levels, large negative tendencies of local relative vorticity occur during the incipient stage. This indicates a decrease of the weak anticyclonic circulation that predominates above $650 \mathrm{hPa}$ (Fig. 9a). The intensifying stage also presents intense negative vorticity tendencies at the mid troposphere (Fig. 9b), which reflects the southwestward movement of the surface low towards the upper level low counterpart (Figs. 3b and $4 b$ ). By the weakening stage, positive values of local relative vorticity tendencies in all levels indicate a decrease in the intensity of cyclonic vorticity throughout the troposphere. During the extratropical transition stage negative tendencies of local vorticity occur mainly at upper levels (Fig. 9b) as Anita moves towards extratropical latitudes.

The horizontal relative vorticity advection (Fig. 9c) is mostly anticyclonic at lower levels for all stages, especially during the intensifying stage. At upper levels, the horizontal relative vorticity advection is cyclonic during all stages except the weakening stage. According with the quasi-geostrophic 
(a)

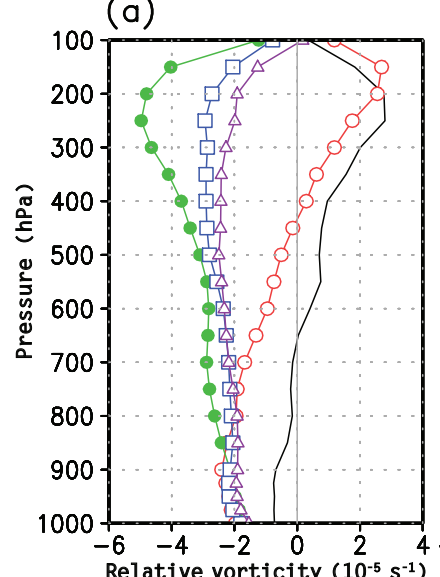

(e)

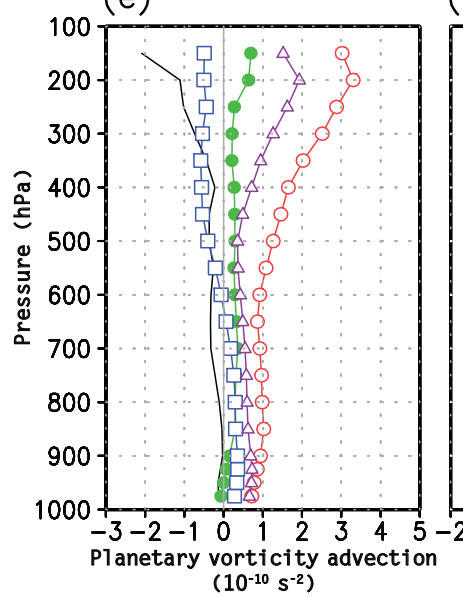

(b)

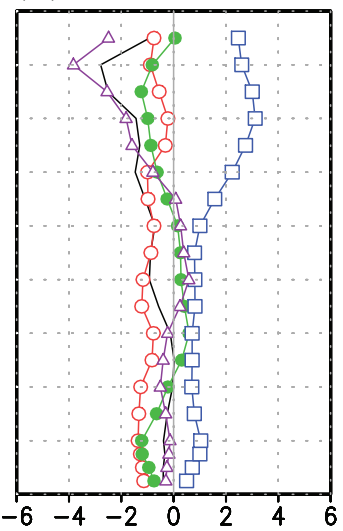

(f) change $\left(10^{-10} \mathrm{~s}^{-2}\right)$

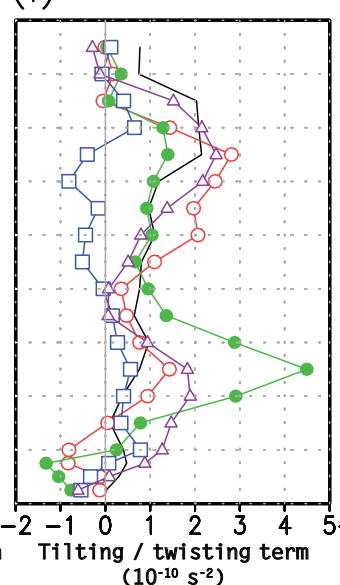

(c)

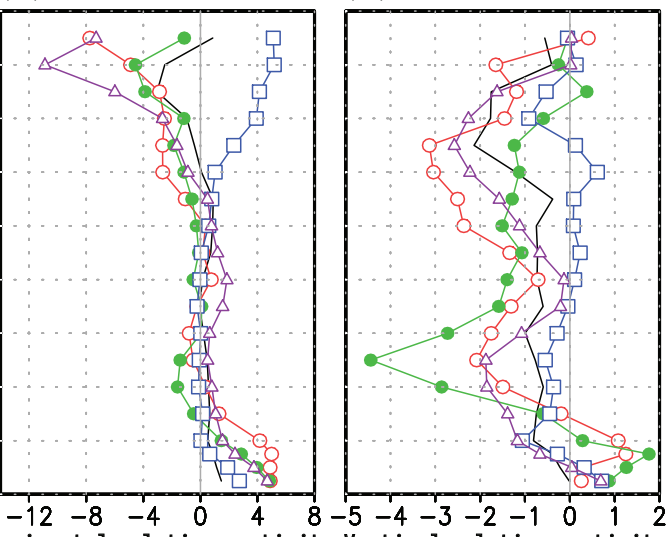

Horizontal relative vorticity Vertical relative vorticity

$(\mathrm{g})^{2}$

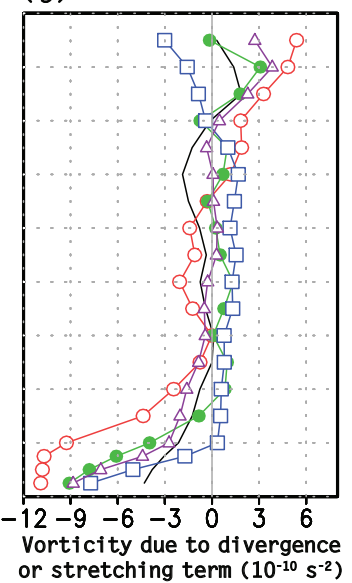

(h)

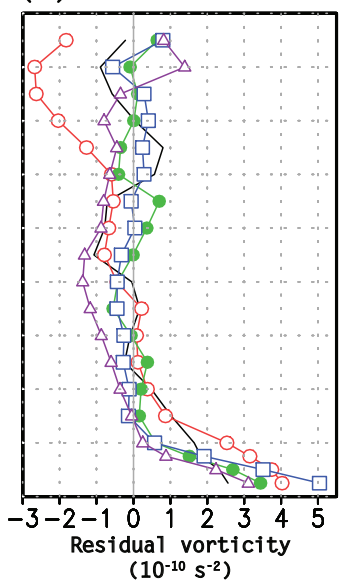

Legend: - Incipient stage o- Intensifying stage - Mature stage

$\square-\square$ Weakening stage $\Delta \Delta$ Extratropical transition stage

Figure 9. Vertical profiles of (a) relative vorticity $\left(10^{-5} \mathrm{~s}^{-1}\right)$, (b) local relative vorticity change, (c) horizontal relative vorticity advection, (d) vertical relative vorticity advection, (e) planetary vorticity advection, (f) the tilting or twisting term, (g) vorticity due to divergence or stretching term and (h) the residual vorticity. Units of (b)-(h) are in $10^{-10} \mathrm{~s}^{-2}$. The vertical profiles were calculated as daily averages (from 00 UTC to 18 UTC) for each stage of Anita, as indicated by the red curly brackets in Fig. 1b.

omega equation (Trenberth 1978; Maddox and Doswell 1982), upward (downward) motion occurs where horizontal cyclonic (anticyclonic) advection increases with height. Thus, the vertical change of the horizontal relative vorticity advection in Fig. 9c can explain part of the vertical velocities (Fig. 7a) during some stages (e.g. during the intensifying and the extratropical transition stages and the weakening stage at upper levels). Additionally, the spatial field of the horizontal relative vorticity advection (not shown) depicts an area of cyclonic horizontal relative vorticity advection to the southwest of the surface low at low levels during the intensifying stage, contributing to Anita's southwestward motion. Moreover, it is noteworthy to mention that the upper level anticyclonic advection during the weakening stage is the main mechanism responsible for the positive upper level vorticity changes seen in Fig. $9 \mathrm{~b}$ for this stage.

The vertical relative vorticity advection (Fig. 9d) is contributing to the cyclonic tendencies at mid- and upper levels mainly during incipient, the intensifying, the mature and the extratropical transition stages, partly reflecting the large intensity of the vertical motion, but also indicating that the vertical gradients of vorticity are more intense at these levels and stages. Additionally, these cyclonic contributions from the vertical relative vorticity advection indicate the transport of cyclonic vorticity from lowto upper levels by the convective processes.

Positive (negative) values of the planetary vorticity advection (Fig. 9e) indicate that the mean meridional flow in the box over the surface low is mostly southward (northward). Even though planetary vorticity advection (Fig. 9e) tends to be negatively associated with horizontal relative vorticity advection (Fig. 9e; Lau 1979), particularly in the mid-latitudes where westerly winds predominate, it can also reinforce the local relative vorticity tendencies due to horizontal relative vorticity advection in some cases, commonly in the subtropics (e.g. during the incipient and mature stages of Anita at upper levels). Fig. 9e shows that the 
planetary vorticity advection is cyclonic and increases with height from mid- to upper levels during the incipient phase, contributing to the upward motion (Fig. 7a). For the intensifying and the extratropical transition stages, however, the planetary vorticity advection is anticyclonic throughout the atmospheric column (Fig. 9e) and thus acts to offset some of the cyclonic tendencies at middle and upper levels due to horizontal relative vorticity advection (Fig. 9c).

The profile of the tilting term (Fig. 9f) shows a large amount of cancelation with the profile of vertical relative vorticity advection (Fig. 9d) in all stages and levels, and thus during the incipient, intensifying, mature and extratropical transition stages, the tilting term contributes to the anticyclonic tendencies throughout the upper troposphere. The propensity for cancelation between the vertical relative vorticity advection and the tilting term is also verified in previous studies of cyclones that underwent extratropical transition (e.g. DiMego and Bosart 1982; Sinclair 1993). Large values in the tilting term are related to intense vertical shear of the horizontal wind and horizontal gradients of rtical motion.

The vertical profiles of vertical relative vorticity advection and tilting term (Figs. 9d and f, respectively) refer to higherorder terms of the vorticity balance that are usually neglected for analyses of synoptic scale motions. Neglecting these two terms when calculating the residual vorticity does not significantly change the qualitative distribution of the residual vorticity profile (not shown). However, it can lead to substantial overestimation underestimation of the vorticity tendencies for some stages and levels, and consequently to misguided interpretation of the residual vorticity.

The vorticity due to divergence, also known as the stretching term, includes contributions from the vorticity and divergence product $(\mathrm{ZD})$, and from the planetary vorticity and divergence product (FD), as in the analyses of Morrison and Businger (2001). Contributions from ZD are usually smaller than those from FD, and some studies explore them individually (e.g. Grotjahn 1996). Convergence of mass in the atmosphere is related to shrinking of the vortex tubes and consequent production of cyclonic vorticity, with the opposite being true for divergence (Martin 2006, 132-133). The profile of vorticity due to divergence
(Fig. 9g) for Anita indicates that, at low levels, convergence is the main process responsible for the cyclonic vorticity tendencies, with the intensifying stage showing the most intense contributions of convergence below $800 \mathrm{hPa}$. Karyampudi and Pierce (2002) investigated the formations of three tropical cyclogenesis cases over the Eastern Atlantic and also found that cyclonic tendencies at low levels are predominantly contributed by the stretching term, as a result of low-level convergence. During the weakening stage of Anita, divergence (not shown) is the main forcing for the anticyclonic tendencies in the $750 \mathrm{hPa}$ to $350 \mathrm{hPa}$ layer.

Also of note is that, during the incipient stage at upper and middle levels, cyclonic horizontal relative vorticity advection (Fig. 9c), planetary vorticity advection (Fig. 9e) and vorticity due to divergence (Fig. 9g) are the main components contributing to the observed local relative vorticity tendencies (Fig. 9b). Note, however, that the negative contributions of the vertical relative vorticity advection (Fig. 9d) are mostly cancelled out by the positive contributions of the tilting term (Fig. 9f) during the incipient stage.

Throughout all stages of Anita, the residual vorticity profile (Fig. 9h) acts mainly as a function of the divergence term profile (Fig. 9g), showing opposite contributions and reducing its influence on the local relative vorticity tendencies. It is important to emphasize that, at some regions and atmospheric levels, the divergence of mass is strongly related to the vertical motion. Thus, it is interesting to analyze if convection is acting as a strong forcing for the observed vorticity imbalances given that convective process are also related to the vertical motion. This issue is explored in the next section.

\subsection{Association between the residual fields}

Reed and Johnson (1974) explored the vorticity budget in ridge and trough regions of easterly wave disturbances in the tropical western Pacific. They found that, over the region of most intense convection, the residual vorticity acts like an apparent sink of cyclonic vorticity in the lower troposphere and an apparent source of cyclonic vorticity at upper levels. Virji (1982) analyzed the upper tropospheric vorticity budget over the tropical and subtropical South America and found a spatial correlation between patterns of vorticity imbalances and intense cumulus 
convective activity, suggesting that the vertical advection of vorticity by subgrid-scale convection greatly influences vorticity tendencies.

For Anita, the residual vorticity profiles in Fig. 9h show, for the lower troposphere, a similar pattern of that found by Reed and Johnson (1974), i.e., apparent sinks of cyclonic vorticity (positive values) at low levels. At upper levels, however, only the intensifying stage presents a clear intense apparent source of cyclonic vorticity (negative values). During the extratropical transition stage, this source of cyclonic vorticity is less intense d occurs immediately above the low level sink, extending from $800 \mathrm{hPa}$ to $250 \mathrm{hPa}$. This pattern in the vertical profile of the residual vorticity, with an apparent sink below and an apparent source aloft, likely indicates the upward transport of vorticity through convective processes. For the other stages (incipient, mature and weakening), although there is a clear sink of cyclonic vorticity at low levels, Fig. 9h shows only small sources of cyclonic vorticity spread throughout middle and upper levels,

\section{intercalated with small sinks of cyclonic vorticity.}

The spatial pattern of residual fields of the heat and vorticity budgets have been analyzed in order to establish if the ideas of Reed and Johnson (1974) and Virji (1982) also apply to the regions of great convective-scale motions associated with Anita. We have carefully examined these spatial patterns in all pressure levels, and chose to display here the fields for $925 \mathrm{hPa}$, where associations between the residual fields are more apparent and where all stages present a consistent sink of cyclonic vorticity see Fig. 9h). Thus, Fig. 10 shows, for $925 \mathrm{hPa}$, the diabatic term of the thermodynamic equation (shaded) and the residual sinks (green contours) and sources (dashed purple contours) of cyclonic vorticity. Similarly, Fig. 11 depicts, for $925 \mathrm{hPa}$, (shaded) and the stretching term, where positive values indicate divergence (green contours) and negative values indicate convergence (dashed purple contours) of the flow.

In general, Fig. 10 indicates that for all stages there are regions over Anita and its surroundings in which diabatic heating coincides with sinks of cyclonic vorticity. Specifically, many regions with positive values of the residue of the thermodynamic equation also present positive values of the residue of the vorticity equation. In these regions, convection would explain part of the vorticity imbalances. It is interesting to note that, over these regions, the spatial distribution of the residual vorticity (Fig. 10) seems to be negatively associated with the spatial distribution of the stretching term (Fig. 11). Moreover, in these regions, the diabatic term (Fig. 10) also seems to be negatively associated with $S_{w}$ (Fig. 11).

An example of the described associations occurs during the intensifying and the mature stages over Anita, when areas of intense diabatic heating are located over the surface low, coinciding with an apparent cyclonic vorticity sink (see Figs. 10bc). In addition, these areas are characterized by a core of negative contributions by $S_{w}$ and a center of negative values of the stretching term (see Figs. 11b-c).

Similar associations are found in the upper troposphere during some stages over Anita (not shown), but regions of upward motion show in general an apparent source of cyclonic vorticity instead of an apparent sink, supporting the results of Reed and Johnson (1974). At upper levels, regions with negative values of $S_{w}$ (cooling by adiabatic expansion due to upward motion) are characterized by positive vorticity due to divergence, which indicates divergence of the flow. In these regions, the diabatic term is usually positive and there is a source of cyclonic vorticity, that is, negative values of the residual vorticity.

In contrast, over regions where there is no clear association between the residual fields, vorticity due to divergence does not seem to be well associated with the residual vorticity, and likewise $S_{w}$ does not seem to be well associated with the diabatic term.

The patterns described can be explained as follows. Positive (negative) values of the stretching term at the upper (lower) troposphere are associated with divergent (convergent) flow, which at those levels is usually related to upward (upward) motion. Therefore, when the stretching term of the vorticity equation controls the residual vorticity, it means that this residual vorticity is strongly related to processes of vertical motion, which are in turn related to convective activity. Thus, it may be inferred that convection has an important role in the local relative vorticity tendencies. Over areas where no clear association between the residual fields is found, it is hypothesised that convection probably also influences the vorticity tendencies, but more evenly throughout the atmospheric column, in the same way as the 
(a) Incipient

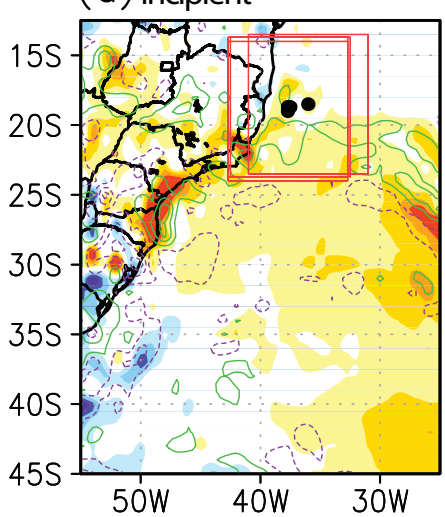

(d) Weakening

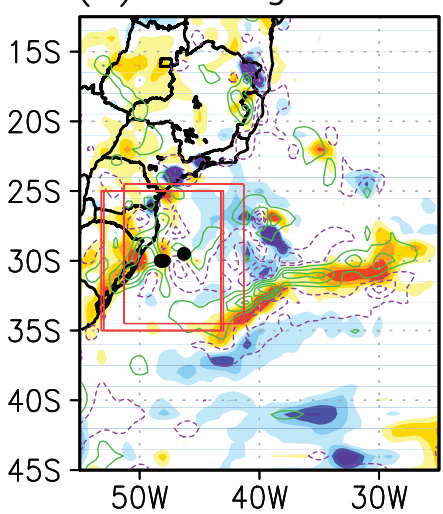

(b) Intensifying

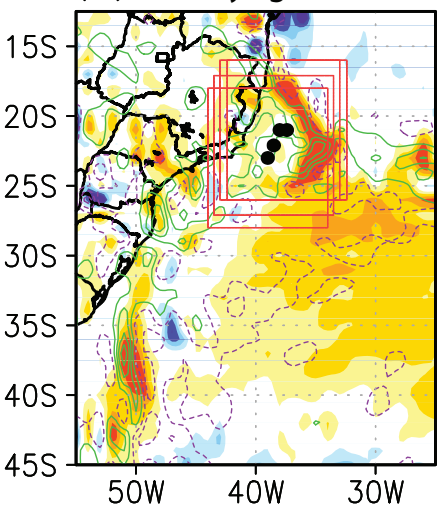

(e) Extratropical transition

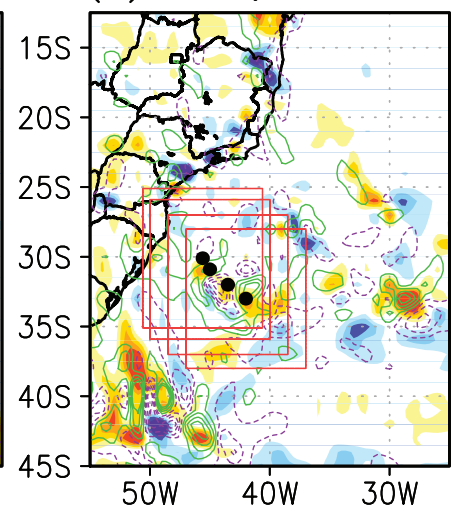

(c) Mature
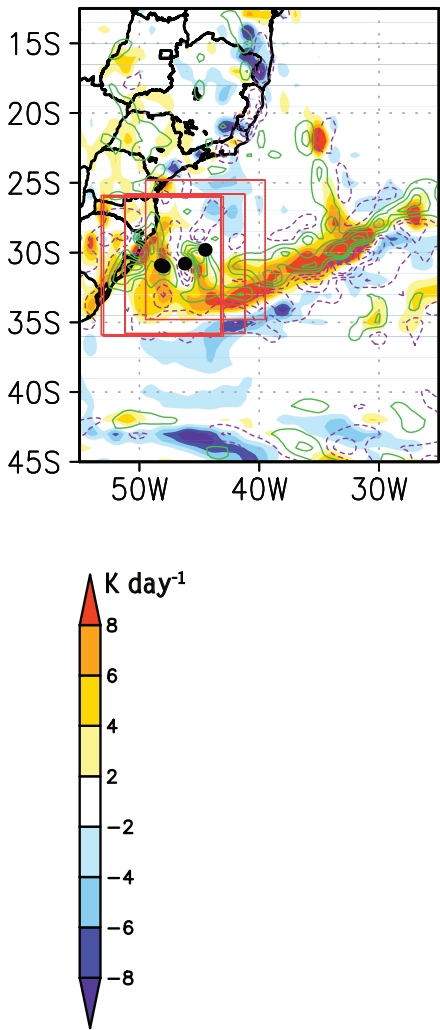

Figure 10. Diabatic term or residue of the thermodynamic equation (shaded, $\mathrm{K} \mathrm{day}^{-1}$ ) and residual vorticity (green contours indicate sinks and purple dashed contours indicate sources of cyclonic vorticity, every $10 \times 10^{-10} \mathrm{~s}^{-2}$ from $-35 \times 10^{-10} \mathrm{~s}^{-2}$ to $35 \times 10^{-10} \mathrm{~s}^{-2}$ ) at $925 \mathrm{hPa}$ for (a) incipient, (b) intensifying, (c) mature, (d) weakening and (e) extratropical transition. The fields were calculated as daily averages (from 00 UTC to 18 UTC) for each stage of Anita, as indicated by the red curly brackets in Fig. 1b. The black dot in each plot indicates the surface low central positioning in each timestep used for the daily average. The $10^{\circ} \times 10^{\circ}$ degree box centered on the surface low at each timestep is also shown in red in each plot.

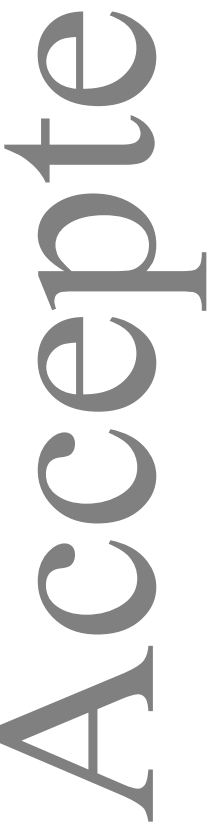

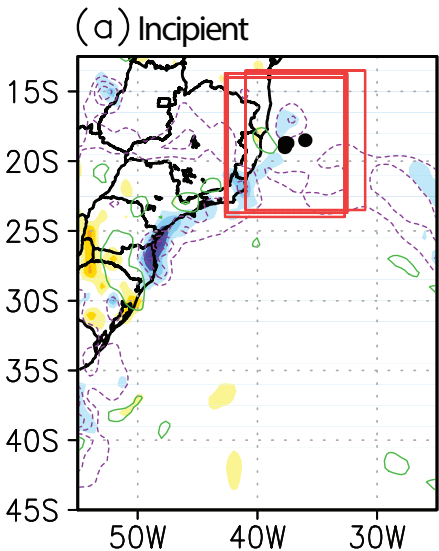

(b) Intensifying

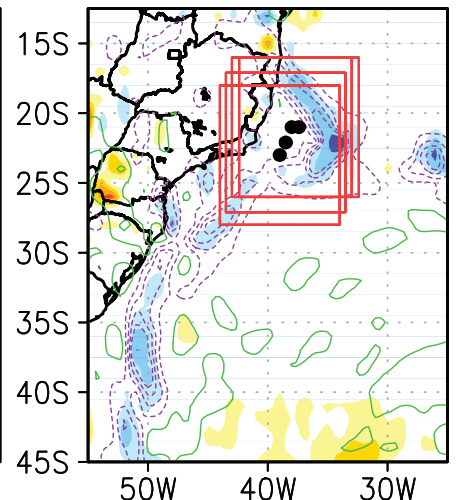

(e) Extratropical transition

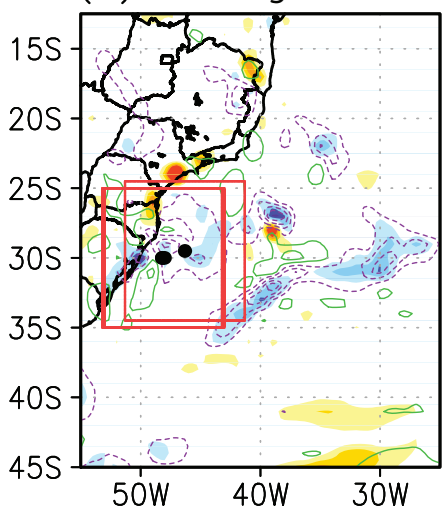

(c) Mature
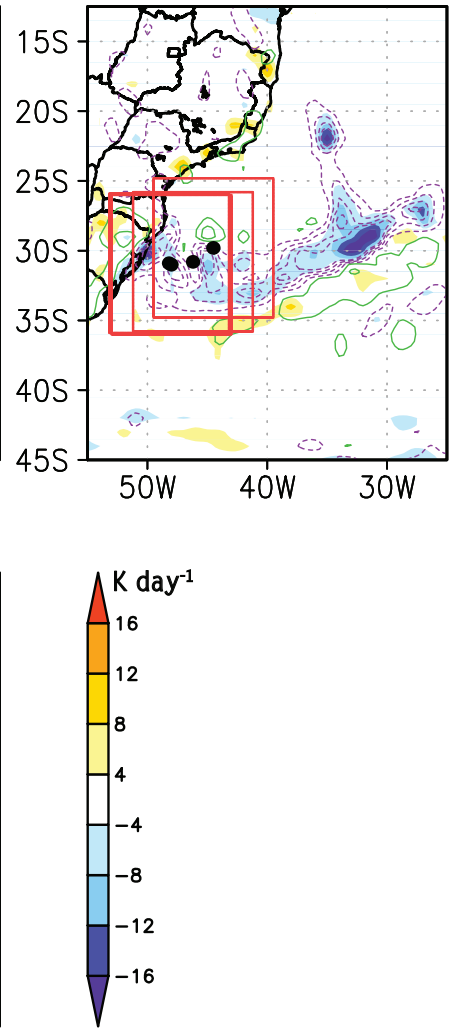

Figure 11. $S_{w}$ (shaded, $\mathrm{K} \mathrm{day}^{-1}$ ) and the stretching term of the vorticity equation (green contours indicate divergence and purple dashed contours indicate convergence of the flow, every $10 \times 10^{-10} \mathrm{~s}^{-2}$ from $-35 \times 10^{-10} \mathrm{~s}^{-2}$ to $35 \times 10^{-10} \mathrm{~s}^{-2}$ ) at $925 \mathrm{hPa}$ for (a) incipient, (b) intensifying, (c) mature, (d) weakening and (e) extratropical transition. The fields were calculated as daily averages (from 00 UTC to 18 UTC) for each stage of Anita, as indicated by the red curly brackets in Fig. 1 b. The black dot in each plot indicates the surface low central positioning in each timestep used for the daily average. The $10^{\circ} \times 10^{\circ}$ degree box centered on the surface low at each timestep is also shown in red in each plot. 
divergence associated with the vertical motion can be distributed throughout the troposphere, without being concentrated at only some levels.

Thus, in general, in regions and levels with upward motion $\left(S_{w}<0\right)$ where associations between the residual fields of the heat and vorticity budget are found, it is observed that apparent sources of cyclonic vorticity are related to divergence, whilst apparent sinks of cyclonic vorticity are related to convergence of the flow. This indicates the upward transport of vorticity through convective processes.

It is important to remember that other subgrid-scale processes (other than convection) which could not be resolved by the synoptic scale variables or included in the equations can also influence the vorticity tendencies. Moreover, it is important to highlight that, at upper levels, these associations between the residual fields are not as evident as in low levels, because both the residual vorticity and the stretching term field at upper levels are noisier, and because at upper levels the stretching term is not so well associated with the vertical motion field.

\section{Summary and conclusions}

This paper has explored the synoptic, dynamic and thermodynamic evolution of a subtropical cyclone which occurred over the South Atlantic near the Brazilian coast in March 2010. The storm was monitored by NRL as Invest 90Q and named Anita by some Brazilian meteorological centers. Here, five stages were Selected to illustrate Anita's evolution.

Analysis of the Cyclone Phase Space (CPS) showed that Anita initially had hybrid characteristics (a warm lower core and a cold upper core). The surface low pressure center developed around $19^{\circ} \mathrm{S}-37^{\circ} \mathrm{W}$ over warm SST anomalies and prior to the cyclonic circulation at low levels, which later extended upward. By the incipient stage, diffluence at $200 \mathrm{hPa}$ over the surface low and contributed to increase the rising motions. During the intensifying stage, diffluence also occured over the surface low at the $200 \mathrm{hPa}$ trough exit of an upper level low located southwest of Anita, which caused divergence aloft and contributed to enhance upward motions throughout the atmosphere, consequentely intensifying the low pressure core and enhancing convergence at low levels. Thus, this upper level low provided dynamical support for further cyclone deepening and favored its southwestward motion. By this stage, moisture flux convergence and warm air advection at low levels increased considerably, and two main synoptic scale cloud bands extended along Brazil's coast. In the following hours, the surface low of Anita started to merge with the upper level low, and by the mature stage the low pressure core was aligned throughout the troposphere, with the cloud bands organized in a spiral shape with a relative lack of clouds over the cyclone core. In the upper troposphere, a strong forward-falling ridge upstream from the upper level low separated from the main stream, forming a closed anticylonic circulation south of Anita's cut-off low. This northsouth dipole pattern remained quasi-stationary for 24 hours and prevented the earlier displacement of Anita towards extratropical latitudes. By the weakening stage, however, a large trough in the main stream approaching the rear of Anita's cut-off low at upper levels contributed to weaken the dipole pattern, and the cyclonic circulation decreased throughout the troposphere along with low level moisture flux convergence. By the extratropical transition stage, with the upper level dipole pattern dissipated, Anita moved southeast and underwent extratropical transition whilst merging with a mid-latitude frontal cyclone.

Vertical profiles of the maximum wind speed over the surface low area were consistent with the thermal wind arguments used in CPS to classify the nature of cyclones. During the subtropical phase, winds decrease with height from the surface to the mid-troposphere and then increase again through the upper troposphere. During extratropical transition, however, the wind intensity increases with height throughout the troposphere.

It was found that low level diabatic heating and horizontal temperature advection (warm during the intensifying stage and cold during the mature stage) were the main mechanisms responsible for the local temperature tendencies at low levels during the main subtropical stages (the intensifying and mature stages). These two mechanisms were therefore essential for the subtropical development. By the weakening stage, diabatic heating decreased considerably at low levels (and throughout the troposphere). During extratropical transition, however, diabatic cooling together with adiabatic cooling and warm air advection were found to be the main mechanisms to influence the local temperature tendencies at low levels. Note that diabatic cooling 
at low levels occurred only once Anita underwent extratropical transition, i.e., all stages prior to the extratropical transition presented diabatic heating at low levels.

The common features found in both subtropical and extratropical intensification phases of Anita (intensifying and extratropical transition stages, respectively) were: 1) intensification of the cyclone throughout the troposphere; 2) cyclonic vorticity horizontal advection increasing with height, which contributed to enhance upward motions; and 3) diffluent flow at $200 \mathrm{hPa}$ over the surface low, leading to divergence aloft and contributing to increase vertical motions.

During all stages, it was found that: 1) convergence was the main process responsible for the cyclonic tendencies in the lower troposphere; 2) diabatic temperature changes mostly opposed the temperature changes caused by $S_{w}$ at mid- and upper- levels; and 3) the residual vorticity primarily acted to destroy some of the vorticity changes due to processes of convergence and divergence. Associations between the residual vorticity field and the esidual of the thermodynamic equation field were also examined verify how synoptic-scale convective processes relate to the vorticity tendencies. In general, over Anita and its surroundings, in regions and levels with upward motion $\left(S_{w}<0\right)$ where such associations occur, apparent sinks of cyclonic vorticity were related to negative vorticity due to divergence (i.e., convergent flow), whilst apparent sources of cyclonic vorticity were related to positive vorticity due to divergence (i.e., divergent flow).

Moreover, these associations between the residual vorticity and hermodynamic fields were found when the following conditions were satisfied:

1. The residual vorticity should primarily be a function of the stretching term, with opposite contributions;

2. Diabatic heating should primarily be a function of $S_{w}$, which is commonly negative for upward motion.

Condition (1) implies that the residual vorticity should be related to convergence/divergence of the flow, which at some atmospheric levels and regions is strongly associated with upward motion, which is in turn related to convective activity. Condition (2) implies that diabatic heating should be mostly due to upward motion, therefore also matching the condition of being related to convective activity. Thereby, it was found that over Anita and its surroundings, there were some regions and levels where convection played an important role in the local relative vorticity tendencies. When no clear associations between the residual fields were found, it was hypothesized that convection likely also influences the local relative vorticity tendencies, but more evenly throughout the troposphere.

\section{Acknowledgements}

The authors would like to thank the United States Naval Research Laboratory for providing the special satellite imagery used in this study, NCEP for the FNL Analysis and NOAA/OAR/ESRL PSD for the NOAA High Resolution SST data used. The authors are also grateful to Dr. Shigetoshi Sugahara for the cyclone tracking algorithm and to Dr. Robert Hart for the CPS algorithm. Finally, the authors would like to thank the anonymous reviewers for their helpful and constructive comments that greatly contributed to improving the final version of this paper. The first author also thanks the INterdisciplinary CLimate INvestigation cEnter from University of São Paulo (INCLINE/USP) for the support received. This research was partially funded by CAPES and FAPESP (Proc. No. 2010/03340-9).

\section{References}

\section{References}

$\begin{array}{rrrrr}\text { American } & \text { Meteorological } & \text { Society. cited: 2016. Subtropical } \\ \text { cyclone. Glossary of } & \text { Meteorology. [Available online at: }\end{array}$ http://glossary.ametsoc.org/wiki/Subtropical_cyclone ].

Atmosfera Meteorologia. 2010. Statement: Rare South Atlantic Tropical Storm Designated Anita. [Available online at: http://www.atmet.com.br/twitter/2010/03/20100312_STATEMENT_AN ].

Azad R, Sorteberg A. 2014a. The Vorticity Budgets of North Atlantic Winter Extratropical Cyclone Life Cycles in MERRA Reanalysis. Part I: Development Phase*. Journal of the Atmospheric Sciences 71(9): 31093128, doi:10.1175/JAS-D-13-0267.1.

Azad R, Sorteberg A. 2014b. The Vorticity Budgets of North Atlantic Winter Extratropical Cyclone Life Cycles in MERRA Reanalysis. Part II: Decaying Phase*. Journal of the Atmospheric Sciences 71(9): 3129-3143, doi:10.1175/ JAS-D-13-0266.1.

Bentley AM, Keyser D, Bosart LF. 2016. A Dynamically Based Climatology of Subtropical Cyclones that Undergo Tropical Transition in the North Atlantic Basin. Monthly Weather Review 144(5): 2049-2068, doi:10.1175/ MWR-D-15-0251.1. 
Browning SA, Goodwin ID. 2013. Large-Scale Influences on the Evolution of Winter Subtropical Maritime Cyclones Affecting Australia's East Coast. Monthly Weather Review 141(7): 2416-2431, doi:10.1175/ MWR-D-12-00312.1.

Carlson TN. 1991. Midlatitude weather systems. Harper Collins: London, UK.

Caruso SJ, Businger S. 2006. Subtropical Cyclogenesis over the Central North Pacific*. Weather and Forecasting 21(2): 193-205, doi:10.1175/WAF914.1.

Chu JH, Yanai M, Sui CH. 1981. Effects of cumulus convection on the vorticity field in the tropics Part-I: The large scale budget. Journal of the Meteorological Society of Japan 59(4): 535-546.

CPTEC-INPE. 2013. Center for Weather Forecasting and Climate Studies - National Institute for Space Research. [Available online at: http://www.cptec.inpe.br/].

da Rocha RP, Caetano E. 2010. The role of convective parameterization in the simulation of a cyclone over the South Atlantic. Atmósfera 23(1): 1-23.

da Rocha RP, Sugahara S, da Silveira RB. 2004. Sea Waves Generated by Extratropical Cyclones in the South Atlantic Ocean: Hindcast and Validation against Altimeter Data. Weather and Forecasting 19(2): 398-410, doi:10. 1175/1520-0434(2004)019〈0398:SWGBEC $\rangle 2.0 . C O ; 2$.

Davis CA. 2010. Simulations of Subtropical Cyclones in a Baroclinic Channel Model. Journal of Atmospheric Sciences 67(9): 2871-2892, doi:10.1175/ 2010JAS3411.1.

Dias Pinto JR, Reboita MS, da Rocha RP. 2013. Synoptic and dynamical analysis of subtropical cyclone Anita (2010) and its potential for tropical transition over the South Atlantic Ocean. Journal of Geophysical Research: Atmospheres 118(19): 10 870-10 883, doi:10.1002/jgrd.50830.

DiMego GJ, Bosart LF. 1982. The Transformation of Tropical Storm Agnes into an Extratropical Cyclone. Part II: Moisture, Vorticity and Kinetic Energy Budgets. Monthly Weather Review 110(5): 412-433, doi:10.1175/ 1520-0493(1982)110<0412:TTOTSA $\rangle$ 2.0.CO;2.

Dutton JA. 1986. The ceaseless wind: an introduction to the theory of afmospheric motion. Dover Publications Inc: Mineola, NY.

Evans JL, Braun A. 2012. A Climatology of Subtropical Cyclones in the South Atlantic. Journal of Climate 25(21): 7328-7340, doi:10.1175/ JCLI-D-11-00212.1.

Evans JL, Guishard MP. 2009. Atlantic Subtropical Storms. Part I: Diagnostic Criteria and Composite Analysis. Monthly Weather Review 137(7): 20652080, doi:10.1175/2009MWR2468.1.

Fritz C, Wang Z. 2014. Water Vapor Budget in a Developing Tropical Cyclone and Its Implication for Tropical Cyclone Formation. Journal of the Atmospheric Sciences 71(11): 4321-4332, doi:10.1175/JAS-D-13-0378.1.

González-Alemán JJ, Valero F, Martín-León F, Evans JL. 2015. Classification and Synoptic Analysis of Subtropical Cyclones within the Northeastern Atlantic Ocean*. Journal of Climate 28(8): 3331-3352, doi:10.1175/ JCLI-D-14-00276.1.

Gozzo LF, da Rocha RP. 2013. Air-Sea Interaction Processes Influencing the Development of A Shapiro-Keyser Type Cyclone over the Subtropical South Atlantic Ocean. Pure and Applied Geophysics 170(5): 917-934, doi:10.1007/ s00024-012-0584-3.

Gozzo LF, da Rocha RP, Reboita MS, Sugahara S. 2014. Subtropical Cyclones over the Southwestern South Atlantic: Climatological Aspects and Case Study. Journal of Climate 27(22): 8543-8562, doi:10.1175/
JCLI-D-14-00149.1.

Grotjahn R. 1996. Vorticity Equation Terms for Extratropical Cyclones. Monthly Weather Review 124(12): 2843-2858, doi:10.1175/1520-0493(1996) 124<2843:VETFEC $>2.0 . \mathrm{CO} ; 2$.

Guishard MP, Evans JL, Hart RE. 2009. Atlantic Subtropical Storms. Part II: Climatology. Journal of Climate 22(13): 3574-3594, doi:10.1175/ 2008JCLI2346.1.

Guishard MP, Nelson EA, Evans JL, Hart RE, OConnell DG. 2007. Bermuda subtropical storms. Meteorology and Atmospheric Physics 97(1-4): 239-253, doi:10.1007/s00703-006-0255-y.

Hart RE. 2003. A Cyclone Phase Space Derived from Thermal Wind and Thermal Asymmetry. Monthly Weather Review 131(4): 585-616, doi:10. 1175/1520-0493(2003)131<0585:ACPSDF $\rangle 2.0 . C O ; 2$.

Hirschberg PA, Fritsch JM. 1991. Tropopause Undulations and the Development of Extratropical Cyclones. Part II: Diagnostic Analysis and Conceptual Model. Monthly Weather Review 119(2): 518-550, doi:10.1175/ 1520-0493(1991)119〈0518:TUATDO $\rangle 2.0 . C O ; 2$.

Holland GJ, Lynch AH, Leslie LM. 1987. Australian East-Coast Cyclones. Part I: Synoptic Overview and Case Study. Monthly Weather Review 115(12): 3024-3036, doi:10.1175/1520-0493(1987)115〈3024:AECCPI $\rangle$ 2.0.CO;2.

Hopkins LC, Holland GJ. 1997. Australian heavy-rain days and associated east coast cyclones: 1958-92. Journal of Climate 10(4): 621-634, doi:10.1175/ 1520-0442(1997)010〈0621:AHRDAA $>2.0 . C O ; 2$.

Iwabe CMN, da Rocha RP. 2009. An event of stratospheric air intrusion and its associated secondary surface cyclogenesis over the south atlantic ocean. Journal of Geophysical Research: Atmospheres 114(D9), doi:10.1029/ 2008JD011119. D09101.

Karyampudi VM, Pierce HF. 2002. Synoptic-Scale Influence of the Saharan Air Layer on Tropical Cyclogenesis over the Eastern Atlantic. Monthly Weather Review 130(12): 3100-3128, doi:10.1175/1520-0493(2002)130<3100: SSIOTS $>2.0 . \mathrm{CO} ; 2$.

Lau N. 1979. The observed structure of tropospheric stationary waves and the local balances of vorticity and heat. Journal of Atmospheric Sciences 36(6): 996-1016.

Liou CS, Elsberry RL. 1987. Heat Budgets of Analyses and Forecasts of an Explosively Deepening Maritime Cyclone. Monthly Weather Review 115(9): 1809-1824, doi:10.1175/1520-0493(1987)115〈1809:HBOAAF $>2.0 . C O ; 2$.

Lupo AR, Smith PJ, Zwack P. 1992. A Diagnosis of the Explosive Development of Two Extratropical Cyclones. Monthly Weather Review 120(8): 1490-1523, doi:10.1175/1520-0493(1992)120<1490:ADOTED $>2.0 . C O ; 2$.

Maddox RA, Doswell CA. 1982. An Examination of Jet Stream Configurations, $500 \mathrm{mb}$ Vorticity Advection and Low-Level Thermal Advection Patterns During Extended Periods of Intense Convection. Monthly Weather Review 110(3): 184-197, doi:10.1175/1520-0493(1982)110<0184:AEOJSC >2.0.CO; 2.

Martin JE. 2006. Mid-Latitude Atmospheric Dynamics: A First Course. John Wiley \& Sons, Ltd: Chichester, UK.

McBride JL. 1981. Observational Analysis of Tropical Cyclone Formation. Part III: Budget Analysis. Journal of the Atmospheric Sciences 38(6): 1152-1166, doi:10.1175/1520-0469(1981)038<1152:OAOTCF $\rangle$ 2.0.CO;2.

Moore RW, Martius O, Davies HC. 2008. Downstream development and Kona low genesis. Geophysical Research Letters 35(20): L20814, doi:10.1029/ 
2008GL035502.

Morrison I, Businger S. 2001. Synoptic Structure and Evolution of a Kona Low. Weather and Forecasting 16(1): 81-98, doi:10.1175/1520-0434(2001) 016<0081:SSAEOA $>2.0 . \mathrm{CO} ; 2$.

National Centers for Environmental Prediction/National Weather Service/NOAA/US Department of Commerce. 2000. NCEP FNL Operational Model Global Tropospheric Analyses, continuing from July 1999. [Available online at: http://dx.doi.org/10.5065/D6M043C6 ], Accessed 2 May 2010.

Otkin J, Martin J. 2004. A synoptic climatology of the subtropical kona storm. Monthly Weather Review 132(6): 1502-1517, doi:10.1175/1520-0493(2004) 132〈1502:ASCOTS $>2.0 . \mathrm{CO} ; 2$.

Pezza AB, Simmonds I. 2005. The first South Atlantic hurricane: Unprecedented blocking, low shear and climate change. Geophysical Research Letters 32(15): L15 712, doi:10.1029/2005GL023390.

Raymond DJ, López Carrillo C. 2011. The vorticity budget of developing 1) typhoon Nuri (2008). Atmospheric Chemistry and Physics 11(1): 147-163, doi:10.5194/acp-11-147-2011.

Reboita MS, da Rocha RP, Ambrizzi T, Sugahara S. 2010. South Atlantic Ocean cyclogenesis climatology simulated by regional climate model (RegCM3). Climate Dynamics 35(7-8): 1331-1347, doi:10.1007/s00382-009-0668-7.

Reed RJ, Johnson RH. 1974. The Vorticity Budget of Synoptic-Scale Wave Disturbances in the Tropical Western Pacific. Journal of Atmospheric Sciences 31(7): 1784-1790, doi:10.1175/1520-0469(1974)031〈1784:TVBOSS $\rangle$ 2.0.CO;2.

Rolfson DM, Smith PJ. 1996. A Composite Diagnosis of Synoptic-Scale Extratropical Cyclone Development over the United States. Monthly Weather Review 124(6): 1084-1099, doi:10.1175/1520-0493(1996)124<1084: ACDOSS $>2.0 . \mathrm{CO} ; 2$.

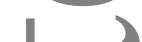

Simpson RH. 1952. Evolution of the Kona Storm a Subtropical Cyclone. Journal of Meteorology 9(1): 24-35, doi:10.1175/1520-0469(1952)009<0024: EOTKSA $>2.0 . \mathrm{CO} ; 2$.

Sinclair MR. 1993. Synoptic-Scale Diagnosis of the Extratropical Transition of a Southwest Pacific Tropical Cyclone. Monthly Weather Review 121(4): 941960, doi:10.1175/1520-0493(1993)121<0941:SSDOTE $>2.0 . C O ; 2$.

Sinclair MR, Revell MJ. 2000. Classification and Composite Diagnosis of Extratropical Cyclogenesis Events in the Southwest Pacific. Monthly Weather Review 128(4): 1089-1105, doi:10.1175/1520-0493(2000) 128<1089:CACDOE $>2.0 . \mathrm{CO} ; 2$.

Sugahara S. 2000. Variação Anual da Frequência de Ciclones no Atlântico Sul. In: Proceedings of the 11th Brazilian Congress of Meteorology, Rio de Janeiro. Sociedade Brasileira de Meterologica, pp. 2607-2612.

Trenberth KE. 1978. On the Interpretation of the Diagnostic Quasi-Geostrophic Omega Equation. Monthly Weather Review 106(1): 131-137, doi:10.1175/ 1520-0493(1978)106<0131:OTIOTD $\rangle$ 2.0.CO;2.

Virji H. 1982. An Estimate of the Summertime Tropospheric Vorticity Budget over South America. Monthly Weather Review 110(3): 217-224, doi:10.1175/ 1520-0493(1982)110<0217:AEOTST $\rangle$ 2.0.CO;2.

Wang Z. 2012. Thermodynamic Aspects of Tropical Cyclone Formation. Journal of the Atmospheric Sciences 69(8): 2433-2451, doi:10.1175/JAS-D-11-0298. 1.

This article is protected by copyright. All rights reserved. 